University of Rhode Island

DigitalCommons@URI

Open Access Master's Theses

2017

\title{
Utilizing Empirical Eigenfunctions and Neural Network to Describe and Model RI Coastal Morphology
}

Sierra Madeline Davis

University of Rhode Island, sierradavis@uri.edu

Follow this and additional works at: https://digitalcommons.uri.edu/theses

\section{Recommended Citation}

Davis, Sierra Madeline, "Utilizing Empirical Eigenfunctions and Neural Network to Describe and Model RI Coastal Morphology" (2017). Open Access Master's Theses. Paper 1125.

https://digitalcommons.uri.edu/theses/1125

This Thesis is brought to you for free and open access by DigitalCommons@URI. It has been accepted for inclusion in Open Access Master's Theses by an authorized administrator of DigitalCommons@URI. For more information, please contact digitalcommons-group@uri.edu. 


\section{UTILIZING EMPIRICAL EIGENFUNCTIONS AND NEURAL NETWORK TO DESCRIBE AND MODEL RI COASTAL MORPHOLOGY \\ BY \\ SIERRA MADELINE DAVIS}

A THESIS SUBMITTED IN PARTIAL FULFILLMENT OF THE REQUIREMENTS FOR THE DEGREE OF

MASTER OF SCIENCE

IN

OCEANOGRAPHY

UNIVERSITY OF RHODE ISLAND 
MASTER OF SCIENCE THESIS

OF

SIERRA MADELINE DAVIS

APPROVED:

Major Professor: John W. King

Thesis Committee: Rebecca S. Robinson

Simon E. Engelhart

Nasser H. Zawia

DEAN OF THE GRADUATE SCHOOL

UNIVERSITY OF RHODE ISLAND

2017 


\begin{abstract}
Southern Rhode Island's microtidal, sandy beaches have been monitored using stadia-style profiling techniques in bi-weekly time intervals during the spring, fall, and winter, and monthly during the summer since the early 1960s. This dataset provides a time-series of cross-sections based on which volumetric changes can be inferred. Early studies utilized these profile volume calculations for spectral analyses, which revealed high-frequency cycles of 1 year and 1.5-5 years attributed to seasonal trends and longshore sediment transport, respectively. Additionally, varved sedimentary records in southern Rhode Island provide locally-derived proxies that indicate North Atlantic climatic drivers such as North Atlantic Oscillation (NAO) influence local weather patterns. Currently, with nearly fifty-five consecutive years of surveying, these lower frequency climatic cycles (5-15 years) can be resolved. This work presents statistical analyses using empirical orthogonal eigenfunctions to describe variations in profile shape as well as spatial and temporal patterns within the timeseries dataset. Dominant cycles within the beach volume time-series are identified through spectral analysis techniques. With these methods, links between those aforementioned Northern Hemisphere climatic cycles and their impact on coastal geomorphology are investigated. Additionally, using nearshore wave climate data derived from a 35-year long dataset (1980-2014) from the nearest United States Army Corps of Engineers' Wave Information Study (WIS) buoy, we attempt to explain the higher-frequency cycles in beach volume change through a correlation analysis for this period. In an effort to model and predict beach volume, methods of Neural
\end{abstract}


Networking, a form of Artificial Intelligence, are applied using wave climate data, mean sea level, and the NAO index as input parameters 


\section{Acknowledgements}

First I would like to thank my advisor, John King, for the opportunities I have had over the last few years. You have provided me with freedom both to explore the topics of this thesis and grow as an independent researcher, while also offering direction when requested. I appreciate your consistent availability to meet with me to discuss topics ranging from coastal geology to my career path after graduate school. I will forever value your financial support in my education.

My core committee members, Simon Engelhart and Rebecca Robinson influenced my graduate career early on. I was inspired and motivated by your classes my first semester as well as in seeing the passion you both have for research and academia. I appreciate your encouragement and constructive ideas in thesis proposal presentations and meetings.

I was introduced to Stephan and Annette Grilli through their enthusiasm to use the beach survey dataset in engineering and predictive capacities. Frequent meetings with you both provided me with a more comprehensive understanding of beach processes and coastal forcing. My coding experience exponentially developed as I began working with you. The methods presented by the Grillis drove the direction of this thesis and for that I am grateful.

A special thanks goes to Gavino Puggioni. Your expertise in statistics and the time-series course you offered was invaluable to my confidence in moving forward with my project.

Many thanks are extended to the members of South Lab - Monique LaFrance Bartley, Danielle Cares, Brian Caccioppoli, Carol Gibson, Sean Scannell, David 
Robinson, and Chip Heil -- for your unending support. I am able to take many field skills and even life lessons with me because of your kindness, patience, and encouragement.

Additional thanks goes to Rob Pockalny, Rick Murray, and Steve Hovan for introducing me to the field of geological oceanography, inviting me on a voyage that changed my life, and encouraging me to pursue my degree at GSO.

Lastly, I would like to thank my family and friends. I am so fortunate to move through these stages in life with such a positive and inspiring group of people. 


\section{TABLE OF CONTENTS}

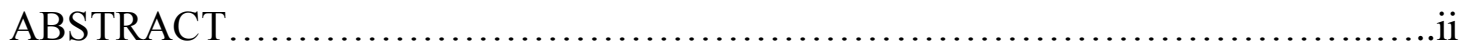

ACKNOWLEDGEMENTS .............................................. iv

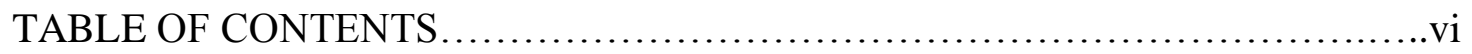

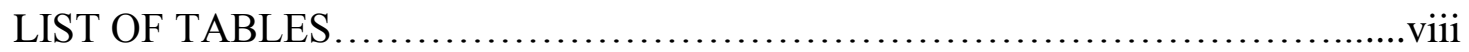

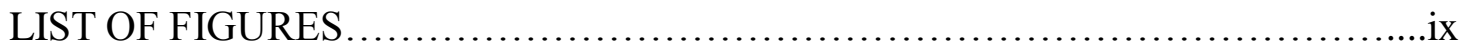

\section{UTILIZING BEACH PROFILE TIME-SERIES AND EMPIRICAL EIGENFUNCTIONS TO ASSESS RI COASTAL MORPHOLOGY}

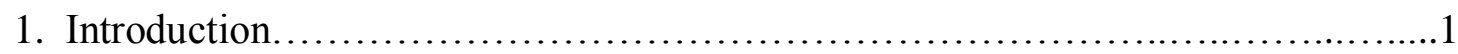

1.1 Statement of the Problem and Research Questions.........................1

1.2 Justification/Significance of the Study and Previous Works...................2

1.3 Geologic Setting of Southern Rhode Island Beach Locations.................5

1.4 Analysis and Modeling Overview.....................................6

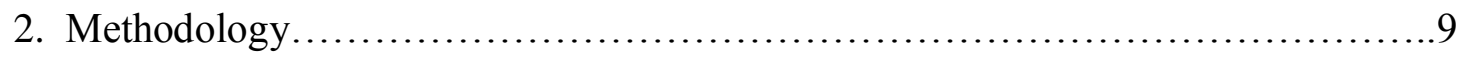

2.1 Stadia Style Beach Profiling........................................ 9

2.2 Beach Survey Data Management, Manipulation, and Volume Calculations...10

2.3 Empirical Orthogonal Eigenfunction Analysis............................11

2.4 Developing a Neural Network..................................... 15

3. Results............................................................. 25

4. Discussion........................................................... 31

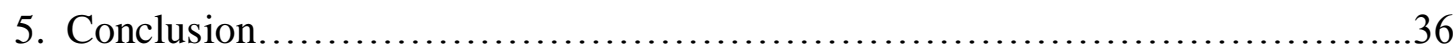

6. Figures and Tables.................................................... 37 
Appendices..........................................................60

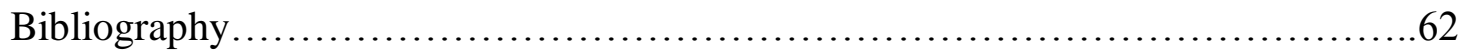




\section{List of Tables}

Table 1. Location and Elevation Changes of $\mathrm{R}_{0}$ Stake for Each Beach.

Table 2. Available Profile Data from Each Beach.

Table 3. Correlation coefficients between WIS parameters, NAO, MSL, and EST-1.

Table 4. Correlation coefficients between all beach volumes.

Table 5. Best fit equations for each mean beach profile.

Table 6. Quantity of Eigenfunctions and the \% variance in profile change they account for.

Table 7. Geologic interpretation of eigenfunction shape in a cross-shore beach profile.

Table 8. Evaluation of MSE and R for training, validation, and testing of NN. 


\section{List of Figures}

Figure 1. Location map of the seven continually surveyed beach profile locations

Figure 2. Location map of Wave Information Studies (WIS) station 63079

Figure 3. Generalized Diagram of Stadia-Style Profiling

Figure 4. Wave Rose of Direction and Number of Incident Waves (WIS Station 63079)

Figure 5. Visual Schematic of a NARX Model

Figure 6. All southern Rhode Island profile-derived beach volumes plotted with time.

Figure 7. Moonstone mean profile plotted with the first eigenfunction.

Figure 8. Mean profiles for all seven beaches.

Figure 9. All eigenfunctions showing cross-shore variations for each beach.

Figure 10. $2^{\text {nd }}$ eigenfunction and coefficient for Misquamicut, with respect to the mean profile.

Figure 11. Power spectrum density plots of corresponding eigenfunction coefficients for EST-1.

Figure 12. Power spectrum density plots of corresponding eigenfunction coefficients for EST-2.

Figure 13. Power spectrum density plots of corresponding eigenfunction coefficients for MIS.

Figure 14. Linear correlations between Neural Network outputs and targets.

Figure 15. Response and error of Neural Network outputs compared to targets.

Figure 16. Error histogram of NN training, validation, and testing. 
Figure 17. Plotted comparison between NN output values and target beach volumes for EST-1. 


\section{Introduction}

\subsection{Statement of the Problem and Research Questions}

Physical and environmental factors including waves, winds, storms, tides, and sea level drive coastal geomorphology. Variations in elevation and slope of a beach profile are the shoreline response to these forcings (Dean \& Dalrymple, 2004). Sustaining datasets that aid in quantifying and modeling the influences of these processes is vital to predicting shoreline position and coastal response (Ruggiero, Voigt, \& Kaminsky, 2000). The University of Rhode Island (URI) has profiled southern Rhode Island beaches since the 1960s, an effort initiated by Dr. Robert L. McMaster (Jon C. Boothroyd, Scot M. Graves, \& Christopher W. Galagan, 1988). This dataset provides a time-series from which one can infer volumetric changes. This study builds upon the limited work that has incorporated these data and capitalizes on the dataset's length to improve understanding of climatic influence on the Rhode Island coast. Utilizing over fifty years of consecutive beach-profiling data along the Rhode Island coast, this study aims to:

1. Describe variations in profile shape and spatial and temporal patterns within the profiling time-series dataset using empirical orthogonal eigenfunctions.

2. Understand the impacts that lower frequency (5-15 year) climatic cycles have on the coastal geomorphology of this region.

3. Model and predict beach profile changes over time using an artificial neural network that incorporates wave parameters derived from Wave Information Studies hindcast data. 
Previously, this type of analysis was not possible due to the limited length of the timeseries; lower-frequency climatic cycles could not be accurately distinguished from the data due to a lack of sampling resolution.

\subsection{Justification/Significance of the Study and Previous Works}

An understanding of coastal geomorphic response to cyclic Northern Hemisphere weather patterns as well as local wave climates has implications for policy-making including coastal resilience and remediation efforts. The seven south facing barrier beaches (Figure 1) that have been continually profiled have coastal morphologies dominated by wave energy and direction (Boothroyd, Friedrich, \& McGinn, 1985; Davis \& Hayes, 1984).

\section{Climatic Cycles and Coastal Geomorphology}

Using the length of the beach survey at the time and spectral analysis, Lacey and Peck (1998) were able to recover high frequency cycles of 1 year and 1.5-5 years, which correspond to seasonal trends and longshore transport, respectively. Now that the time-series spans over fifty years, the beach volume time-series has the potential to resolve lower frequency cycles of up to about 25 years. With additional decades of data, we performed analyses that were not possible at the time of Lacy \& Peck's (1998) study. Consequently, this study seeks to understand the impacts that lower frequency climatic cycles, such as North Atlantic Oscillation (NAO), have on beach volume changes. There are few studies that explore the effects that climate cycles have on coastal geomorphology (Thomas, Phillips, \& Williams, 2010; Thomas, Phillips, Williams, \& Jenkins, 2011) largely due to the limited length and availability

of datasets. However, there is overwhelming evidence that NAO is a prominent 
contributor to atmospheric circulation variability and effects precipitation, wind strength, and consequently wave heights (Durkee et al., 2008; J. W. Hurrell, 1995; Sheridan, 2003). Additionally, varved (annually laminated) sedimentary records in southern Rhode Island provide locally-derived proxies that indicate North Atlantic climatic drivers such as NAO, Atlantic Multidecadal Oscillation, and the Pacific/North American pattern influence local weather patterns (Hubeny, King, \& Reddin, 2011; Hubeny, King, \& Santos, 2006). A strengthening of the Icelandic Low and Azores High pressure systems indicates a positive phase of NAO. This increase in pressure gradient strengthens westerly winds over the eastern United States. Particularly during winter months (November to April), a positive NAO phase also tends to bring higher temperatures, more precipitation, and stronger and more frequent storms to this region.

\section{Coastal Geomorphology, Local Wave Climate, and Sea Level Rise}

Longshore coastal changes are often depicted as shoreline position and beach rotation. Previous works used beach profiles from southern RI to find that shoreline position oscillates throughout the year with rates of change increasing an order of magnitude when responding to storms (Vinhateiro, 2012). On longer timescales, changes in the longshore can impact the orientation and position of the beach. Meanwhile, cross-shore changes are described by changes in the cross-shore profile and area of the cross section with time. The work in this study focuses on the cross-

shore (perpendicular to the coast) changes of the southern Rhode Island coast. Crossshore changes, and the intensity of these changes, happen at various timescales and can impact the sustainability of the beach, surrounding infrastructure, and coastal 
ecosystems (Karunarathna et al., 2016). Because changes in cross-shore beach profiles are thought to be controlled by the incident wave climate, nearshore currents, sediment size and distribution, and sea level (Karunarathna \& Reeve, 2013; Stive \& De Vriend, 1995), it is desirable to quantify and incorporate these parameters in erosion models. These factors are often grouped into categories of long term (decades to centuries), middle term (years to decades), and short term (hours to years) temporal variability (Stive et al., 2002). Using this nomenclature, sea level changes are considered long term, wave climate variations middle term, and wave, tide, surge, and seasonal climate conditions are short-term temporal scale factors. There have been many studies that aim to link these physical forcings to changes in cross-shore transport. (Magnus Larson, Capobianco, \& Hanson (2000) and Horrillo-Caraballo \& Reeve (2008) discovered that there is covariability between waves and profile shape using canonical correlation analysis. Their results suggest that nearshore wave properties can be used toward predictive measurements of beach profile response. The interactions between cross-shore sediment transport and physical processes are complex, often non-linear, and occur in varied spatial and temporal scales (Hashemi, Ghadampour, \& Neill, 2010). This complexity has made statistical and process-based modeling and prediction of beach change a challenge. However, understanding the relationship between these aforementioned physical factors and beach change is of vital importance to coastal engineering and decision making for mitigation and adaptation strategies. In an effort to model and forecast beach change, this work explores the functionality of incorporating wave parameters, sea level, and grainsize 
into a data-driven Neural Network (discussed in section 1.4) to predict beach change over time.

\subsection{Geologic Setting of Southern Rhode Island Beach Locations}

Southern Rhode Island's wave-dominated, microtidal, south-facing coast is comprised of sandy barrier beaches that are separated by rocky headlands. Sediment supply to these beaches is limited to the erosion of barrier spits and glacial headlands, as there are no major rivers that contribute sediment to the shoreline (Boothroyd et al., 1985). Prevailing southwesterly winds drive west to east longshore transport patterns (Morton, Bohlen, Aubrey, \& Miller, 1984). The sandy barrier beaches are backed by saline lagoons (salt ponds).

Seven of these barrier beaches have been continually profiled and their timeseries datasets are examined in this study. From west to east, these beaches are Misquamicut (MIS), Weekapaug (WKG), East Beach 1 (EB-1), East Beach 2 (EB-2), Charlestown Town Beach (CHA-TB), Green Hill (GRH), and Moonstone (MST). This region of coastline is bound by the Long Island Sound to the west, the Block Island Sound to the south, and Narragansett Bay to the east. The individual locations of these beach profiles are important to consider when examining their corresponding volumetric change time-series. Variations in surrounding geology as well as the presence of anthropogenic structures can interfere with littoral transport. Beaches that are directly east or west of a glacial headland (such as WKG, GRH, and MST) might see rates and/or patterns of erosion/accretion that differ from those that are farther away from headlands. As bathymetry becomes shallower toward shore, wave energies 
change due to refraction, diffraction, and reflection (discussed in Section 3.4)

(Sorensen, 2005). Considering this factor, glacial headlands likely experience wave focusing while the surrounding barriers see wave defocusing. Man-made structures such as rock jetties around breachways (as seen to the east of CHA-TB) can alter sediment transport and therefore volumetric change. For these reasons, this work focuses on beaches that see less "noise" in their volume data (i.e. that are not as influenced by surrounding geologic and man-made structures) such as MIS, EST-1, and EST-2. In these beaches, it is hypothesized that cycles attributed to climate and wave energy are more likely to be resolved.

\subsection{Analysis and Modeling Overview}

Empirical Orthogonal Eigenfunction Analysis

Empirical orthogonal eigenfunction (EOF) analysis is a statistical method and form of principal component analysis (PCA) frequently used to describe variation of beach profile elevations in time (Dean \& Dalrymple, 2004). EOF analysis has been applied in a variety of scientific arenas including meteorology (Lorenz, 1956), ecology (Legendre \& Gauthier, 2014), medical imaging (Wachinger, Golland, \& Reuter, 2014), and many others. The advantage of using EOF is that it selects the smallest subset of functions (eigenfunctions) possible to describe a selected maximum amount of variance, where the first eigenfunction accounts for the greatest possible variance in the data. In this study and others, this form of PCA reduces the profile data to a number of eigenfunctions that can reveal spatial and temporal trends in the data. Winant, Inman, and Nordstrom (1975) used two years of profiling data and found that 
change in common features of a beach (berm, terrace, and bar) as well as the mean beach function can be described in just three eigenfunctions that account for most of the variance in profile configuration. In the previously mentioned study by Larson et al. (2000), eigenfunctions reduced noise in profile data allowing for variations in beach profile and wave data to be related through canonical correlation analysis. Karunarathna et al. (2016) used eigenfunctions derived from decades of crosssectional profiles from beaches at various locations (Australia, United Kingdom, Japan) and different sediment compositions (medium to fine sand, sand to gravel) to compare spatial and temporal patterns. Here, using methods of EOF analysis, we are able to determine if prominent trends in RI beach profiles are seen on a temporal scale that could correspond to Northern Hemisphere climatic cycles such as NAO. We are also able to describe sediment transport of beaches from different geologic settings along the southern RI coast.

\section{Developing a Neural Network}

Artificial Neural Networks (ANNs) are supervised self-learning computer methods inspired by neuron connections in the human brain with modeling, predicting, and pattern recognition capabilities. ANNs are comprised of layers of "neurons", or processing units, which pass information from one node to another using weighted inputs and transfer functions. Neurons can be repeatedly adjusted through backpropagation. ANNs are "supervised" in that input values and target output values are supplied and known. The models produced using ANNs are empirically based, although it is important to acknowledge that there are some mechanistic aspects of the models, as chosen input values have previously calculated or suspected effects on the 
target (Nestorov, Rowland, Hadjitodorov, \& Petrov, 1999). In the case of this study, input values include various wave parameters, mean sea level (taken from Newport, RI tide gauge), and the North Atlantic Oscillation Index (all of which are further discussed in Section 2: Methods), while the target parameter is beach volume calculated from cross-sectional profiles. Data-based links between incident waves and beach profile variations have been made in various regions around the world (Karunarathna et al., 2016). Although there have been advancements in forecasting profile change using processed-based and numerical models, these approaches can be computationally expensive and inconsistencies between measured data and the model outputs arise from complexity in the physics underlying the models (Hashemi et al., 2010; Neill, Elliott, \& Hashemi, 2008). Hashemi et al. (2010) developed multiple neural network configurations with physical forcing data as inputs to predict beach profile change; their results proved that ANNs can be effective tools for this type of analysis.

The Army Corps of Engineers developed the Wave Information Studies (WIS) project to produce nationwide wave hindcast model estimates using statistical calculations that incorporate wind and ice fields. There are ten "virtual wave gauge" WIS stations off the coast of Rhode Island and Block Island that provide hourly hindcast estimates of wave height, wind speed, and peak wave period. In this work, WIS data from the virtual buoy station numbered 63079 , located at latitude and longitude 41.25 and -71.42 , respectively was utilized (Figure 2). By using concepts of linear wave theory, wave parameters calculated from WIS station 63079 data are transformed to model near-shore wave conditions. In an effort to relate wave forcing 
to coastal geomorphology, and understand the main contributors to beach profile variance, and model/predict beach volume, the empirical methods of developing a neural network are employed here.

\section{Methodology}

\subsection{Stadia Style Beach Profiling}

A two-person team profiles southern RI beaches bi-weekly during the fall, spring, and winter months and monthly during summer using a Topcon AT-G3 auto level and a stadia rod. See Figure 3 for a schematic of the profiling method. Fall, spring, and winter months bring greater energy to the southern shore through increased wave and wind action, causing more rapid change. For this reason, beaches are profiled bimonthly during this time as opposed to monthly in the summer. Surveying locations are consistent; the locations are marked on the dunes with stakes that have been georeferenced by RTK-GPS to the NAVD88 datum (Vaníček, 1991). Profiles collected prior to the NAVD88 standard were normalized to NAVD88. Prior to RTKGPS technology, Ro stakes were at a fixed location (i.e. concrete monument/telephone pole) that were later measured by RTK-GPS. Restricted by the stadia-rod and transit view, profile elevations have always been accurate to the nearest half a centimeter. Each elevation measurement is referenced to one stake, called $\mathrm{R}_{0}$, which is a known elevation above Mean Lower Low Water (MLLW) and is located on the landward side of the dune crest (Hubeny, 2002). Positionally, the profiles have always been measured in Rhode Island State Plane Feet to third-order accuracy. 


\subsection{Beach Survey Data Management, Manipulation, and Volume Calculations}

After each survey, profile data is recorded in digital files. For visualization purposes, data is managed and cleaned in a spreadsheet prior to manipulation within programing languages. It is important to note that the $\mathrm{R}_{0}$ stakes for all of the beaches have shifted in elevation and position over the years due to stake loss during storms, human activity, and other factors (see Table 1). Because the locations of the $\mathrm{R}_{0}$ have changed throughout the years, beach volumes must be normalized prior to any statistical analysis. Positional changes in the $\mathrm{R}_{0}$ stakes were accounted for by using trigonometry to quantify distance moved in both the $\mathrm{x}$ - and $\mathrm{y}$-directions. The azimuth of the transects between $\mathrm{R}_{0}$ stake changes are assumed to be constant. Elevation changes in the $\mathrm{R}_{0}$ stake are corrected for by adding constants to profiles with $\mathrm{R}_{0}$ elevation values that differ from the original $\mathrm{R}_{0}$. The most seaward point in each profile is extrapolated to the maximum observed distance from $\mathrm{R}_{0}$ for that beach using a polynomial fit from the last three measured distance values. These extrapolated seaward points are also constrained in the y-direction between the lowest observed elevation throughout time and 1 meter above that. Profile elevations are then interpolated every 2-meters in the x-direction and a piecewise cubic spline polynomial interpolation is applied to the entire transect. Following these steps allows for each beach to contain the same amount of cross sectional points for each time step throughout the time series. Each beach does contain a different number of time steps as a result of sampling frequency disruption (environmental factors, stakes being removed, etc.). The number of cross sectional data points is different between beaches due to differing maximum observed values in the $\mathrm{x}$-direction from $\mathrm{R}_{0}$ (Table 2). 
Beach volumes are then calculated using the trapezoidal rule (Dahlquist \& Björck, 2008) to determine the cross-sectional area, bounded by the profile and the one lowest elevation observed throughout the temporal length of the survey. This trapezoidal rule is a common way to calculate beach volume (Dean \& Dalrymple, 2004). The crosssectional area is then multiplied by "one meter" so as to create a "volume" of sand in $\mathrm{m}^{3} / \mathrm{m}$ of shore. Because profile accuracy is vital to estimate volumetric change, each individual profile from every beach was checked for error or abnormities in distance or elevation; these were then corrected for by averaging from surrounding points. Changes in volume between surveys then give a history of erosion and accretion through time. To create a time-series of consistent time intervals, beach volumes are re-interpolated bi-monthly for EOF analysis and monthly for Neural Network target outputs. Months without raw profile data are interpolated from surrounding months. The reasoning for the bi-monthly and monthly frequency sampling are described in the next section (2.3).

\subsection{Empirical Orthogonal Eigenfunction Analysis}

To perform EOF on a beach profiling dataset, one needs multiple profiles over time at a fixed location (Dean \& Dalrymple, 2004). This requirement was attained as described in Section 2.2. After interpolating each profile on an equal 2 meter spatial resolution, bi-monthly profiles were interpolated in the time-series, for this analysis to reduce bias from sampling frequency while also capitalizing on the bi-monthly surveying that occurs $75 \%$ of each year. As stated in Section 1.4, a large amount of variance in beach profiles can be explained through a small set of terms (eigenfunctions and their weighing coefficients). The EOF analysis was 
computationally completed using existing Matlab functions (Chunlüe, 2016). Dean \& Dalrymple (2004) explain the procedure and mathematics behind EOF methods used for beach profiles. Below, their explanation and equations 1-12 are summarized.

For each beach, there were $k$ surveys at consistent (i.e., equally-spaced through interpolation) $i$ locations across the survey from the $\mathrm{R}_{0}$ stake to the largest observed measurement in the $\mathrm{x}$-direction. The total number of $i$ locations was different between beaches (Table 2, Column 4). Each elevation measured at these profiles is represented as $h_{i k}$. A summation of eigenfunctions multiplied by weighing coefficients explains this elevation as shown in Equation 1.

$$
h_{i k}=\sum_{n=I}^{N} C_{n k} e_{n i}
$$

In Equation 1, $C_{n_{k}}$ represents a weighing coefficient, which is a constant, to be determined in the EOF analysis, for the $k$ th survey and the $n$th eigenfunction, while $e_{n_{i}}$ is the $n$th eigenfunction evaluated at the $i$ th location. Eigenfunctions are orthogonal they are independent of each other, which implies Equation 2:

$$
\sum_{I=I}^{I} e_{n i} e_{m i}=\delta_{n m}
$$

Where $\delta_{n m}=1$ if $n=m$; otherwise, it is zero. In order to calculate the coefficients $\left(C_{n k}\right)$ for each $k$ th survey, the mean square error of the fit expressed by Equation 1 for $h_{i k}$ is minimized by the eigenfunctions. Local error $\left(\varepsilon_{i k}\right)$ is shown in the equation below (Equation 3):

$$
\varepsilon_{i k}=h_{i k^{-}} \sum_{n=l}^{N} C_{n k} e_{n i}
$$


The sum of the squares of the errors is minimized over the profile:

$$
\begin{aligned}
& \text { Minimize } \sum_{i=5}^{j} e_{\pi}^{2} \text { with respect to } C_{m k} \\
& 2 \sum_{i=1}^{I}\left(h_{i k}-\sum_{n=1}^{N} C_{n k} e_{n i}\right) e_{m i}=0
\end{aligned}
$$

Using the relationship from Equation 2 (orthogonality) $C_{m k}$, or the coefficient for a given survey, is obtained once eigenfunctions are known:

$$
C_{m k}=\sum_{i=l}^{I} h_{i k} e_{m i}
$$

The total mean-square variance of a beach's profile data, denoted as $\sigma^{2}$, can be explained using the concept of Parseval's theorem - that the square of the variance is equal to the sum of the squares of all of the coefficients over all surveys (Equation 7).

$$
\frac{1}{I K} \sum_{i=1}^{K} \sum_{n=1}^{N} C_{n k}^{2}=\sigma^{2}
$$

To find each eigenfunction, the contribution of that function is maximized using a Lagrange multiplier, $\lambda$, in order to maximize their contribution to the variance. This is outlined in Equations 8. The function is maximized with respect to $e_{n_{m}}$ and then differentiated to obtain:

$$
\sum_{i=1}^{I} e_{n i}\left(\frac{I}{I K} \sum_{k=1}^{K} h_{i k} h_{m k}\right)=\lambda_{m} e_{n}
$$

The co-variance matrix is denoted as $a_{i_{m}}$ :

$$
a_{i m}=\frac{I}{I K} \sum_{k=1}^{K} h_{i k} h_{m k}
$$


And finally, the symmetric matrix equation is:

$$
\sum_{i=1}^{I} a_{i m} e_{n i}=\lambda_{m} e_{n m}
$$

Eigenvalues are related to the total variance by Equation 11.

$$
\sigma^{2}=\sum_{i=1}^{I} \lambda_{n}
$$

To summarize, given the covariance matrix (calculated based on measurements), Equation 10 is a standard eigenvalue problem equation with a symmetric coefficient matrix with $I$ unknowns. As $m$ varies from one to $I$, there are $I$ equations for $I$ unknowns. Because there is one eigenfunction corresponding to each point $I$ in the profiles, $n=I$, and each eigenfunction is associated with an eigenvalue $\lambda_{n}$. Equation 11 is the core principle and reasoning to utilize eigenfunction analysis to understand beach profile spatial and temporal variance.

The above concepts and equations were applied to each beach. From there, the smallest set of eigenfunctions were calculated to describe a set amount of the variance. The variance was first set to $99 \%$ and EOF analysis was run. As described later in Section 3 (Results), most of the variance in profile data (79-98\% depending on the beach) is explained in the mean profile eigenfunction; therefore, the first eigenfunction. This result left little variance for additional eigenfunctions to be extracted and sometimes only one eigenfunction was found. In order to calculate 3-4 eigenfunctions which describe $94-96 \%$ of variance (depending on the beach) in profile data, each beach profile was first demeaned and then the EOF analysis was run, now expressing variance with respect to a reference mean profile. Eigenfunctions are 
plotted together and the spatial variance in the cross-sectional profiles are discussed (Section 3: Results). The coefficients $\left(C_{m k}\right)$ are then plotted in time and spectral analysis is run on the time series to retrieve temporal cyclicity in the data. The multitaper method was used to overcome biases related to autocorrelation within the dataset by testing the amount of red noise in the signal. $95 \%$ confidence intervals were then plotted based on the theoretical red noise spectrum calculated from a 1500 Monte Carlo loop.

\subsection{Developing a Neural Network}

The supervised portion of a Neural Network (NN) is in choosing the input and target parameters.

\section{Determining the Target}

In this work, the target for the $\mathrm{NN}$ is monthly beach volume for East Beach 1. East Beach 1 (EST-1) was chosen based on a few factors:

1. EST-1 is not located near any glacial headlands or jetties which cause variations in wave energies due to refraction/diffraction (Sorensen, 2005). Additionally, in longshore transport, these rigid structures can alter rates of sand erosion/accretion (Frihy \& Lotfy, 1997; Sorensen, 2005). The surveying station for EST-1 is not located near these structures that often create trends in the data (as depicted in Section 3: Results for Moonstone Beach). For this reason, it is assumed that EST1 has the lowest amount of noise within the data.

2. EST-1 has consistently been surveyed with few hiatuses. 
3. There have only been three instances when the $\mathrm{R}_{0}$ stake has been changed for this beach. Other beaches (such as Green Hill) have had many more stake changes, which increases uncertainty.

\section{Determining Input Parameters}

The next step in developing a NN is to decide what input parameters to use based on the target. Here, an understanding of the physical forces that alter crosssectional beach profiles is required. It is important to note that the physical forces included in this study are calculated by numerical functions which oversimplify the complexity of sediment transport in the natural world. However, as discussed in Section 1.2, wave action dominates morphology changes along the Rhode Island coast. It is assumed that mean sea level and the effects of sea level rise also impact coastal change (Nicholls \& Cazenave, 2010). To include these variables in the NN, monthly mean sea level data (1980-2014) is acquired from NOAA's Newport, RI tide gauge website (NOAA, 2017). Because previous work suggests that NAO might also contribute to cross-sectional variation, the NAO index maintained by Hurrell \& NCAR (2017) was obtained from the National Center for Atmospheric Research's website. This index value is a measure of the difference in normalized sea level pressure between Lisbon, Portugal and Reykjavik, Iceland. In an effort to model beach volume change, nearshore wave parameters, mean sea level, and the NAO index are used as input parameters. The following paragraphs explain what wave parameters were chosen and why as well as how they were calculated from WIS data.

Hindcast data from the WIS buoy 63079 is used because it is the closest station to East Beach 1 (Figure 2). The WIS project has hindcast data available every fifteen 
minutes from 1980-2014. Once transformed to shore, monthly statistics of this data were calculated (e.g. mean, maximum, standard deviation) allowing for a 420 time step time-series of nearshore wave parameters. The WIS effort uses discrete spectral wave models and wind fields to calculate significant wave height, $H_{m 0}$, wave peak period, $T$, and wave direction, $\theta$ at each buoy. The water depth at this station is 33 meters. Prior to calculating additional wave characteristics and transferring them to the near shore, assumptions were made:

1. Most of the sand on EST-1 is composed of quartz. The dry bulk sediment density of quartz sand in sea water is $2650 \mathrm{~kg} / \mathrm{m}^{3}$ or a specific density of $s=2.59$ with respect to seawater of average density $1025 \mathrm{~kg} / \mathrm{m}^{3}$ (Bergaya, Theng, \& Lagaly, 2011).

2. Grainsize was measured using sieve techniques on Charlestown Town Beach by undergraduate students in the URI Ocean Engineering Department in 2017. They found that the median sediment size $d_{50}$ for CHA-TB was $0.44 \mathrm{~mm}$. For this study, this value is assumed to be the representative sediment size for all southern RI beaches for the entire length of the time-series.

3. Constants for longshore current, sediment concentration in water, and the Shields parameter calculations are taken from the coastal engineering manual (CEM) (United States Army Corps of Engineers, 2006).

4. A mild slope is assumed, so the breaker index used is 0.8 .

5. Any waves not traveling $90^{\circ}$ on either side of EST-1's transect azimuth $\left(155.1^{\circ}\right)$ are assumed not to refract toward the beach (Figure 4). Only shore incident waves 
were selected $\left(65.1^{\circ}-245.1^{\circ}\right)$. The wave rose for incident waves used in this study is shown in Figure 4.

Considering these assumptions and limitations, wavelength, $L$, wave celerity, $C$, and wave number, $k$, were calculated for the location and depth, 33 meters, of the buoy (Equations 13, 14, and 15, respectively). These parameters are needed to calculate nearshore wave parameters that are known to alter sediment transport (i.e. bottom particle velocity, longshore current, etc.). Calculating nearshore parameters from deep water wave data requires wave transformation, which takes into consideration the effects of shoaling, refraction, and breaking of water waves as they move shoreward (in this simplified analysis, diffraction and reflection cannot be considered). Shoaling refers to the process in which wave height, length, celerity, and other properties alter as waves travel from deep to shallow water. Wave refraction is the directional change of a wave moving in shallow water as the bottom contours change. With refraction of a wave, the portion of the wave crest that is advancing in shallow water moves slower than the portion of the wave advancing in deep water; this bending creates a focusing of wave energy on the beach. The following linear dispersion relationship equation was used for this transformation.

$$
L=L_{o} \cdot \tanh \left(k_{\#} \cdot d\right)
$$

With water depth, $d$ and a deep water wavelength $L_{0}=g T^{2} / 2 \pi$. This equation is solved for each wave period using a Newton-Raphson iteration method - a rootfinding algorithm (Grilli, 2000). With wavelength, one can calculate wave celerity, $C$, (Equation 13) and wave number, $k \#$ (Equation 14). Wave celerity is the speed that a wave travels and the spatial frequency of waves is the wave number. 


$$
\begin{aligned}
& C=\frac{L}{T} \\
& k_{\#}=\frac{2 \cdot \pi}{L}
\end{aligned}
$$

Groups of waves, created by the superposition of many single waves, travel at different speeds than individual waves. This effect is referred to as group celerity, $C_{g}$, and is calculated in Equation 15.

$$
C_{g}=\frac{C}{2}\left(1+\frac{2 k_{\sharp} d}{\sin 2 k_{\sharp} h}\right)
$$

The shoaling coefficient, $K_{s}$, can be calculated using the group celerity in both deep and shallow waves (Equation 16) where $C_{g o}$ is group velocity in deep water and $C_{g}$ in shallow water.

$$
K_{S}=\sqrt{\frac{c_{g o}}{c_{g}}}
$$

To calculate the water depth at breaking, $d_{b}$, and the wave height at breaking, $H_{b}$, one needs to calculate the refraction coefficient, $K_{r}$ (Equation 17), which uses the concepts of Snell's Law.

$$
K_{r}=\sqrt{\frac{\cos \left(\theta_{d}-155^{\circ}\right)}{\cos \left(\theta_{s}-155^{\circ}\right)}}
$$

In Equation 18, $\theta_{d}$ refers to the wave direction in deep water, $\theta_{s}$ refers to the wave direction in shallow water, and we are assuming that the waves are breaking perpendicular to the southern RI coast $\left(155^{\circ}\right)$. The depth at breaking equation (Equation 18) also requires a breaker index, which was previously determined as 0.8 , or denoted here as kappa. 


$$
d_{b}=\frac{g^{\frac{1}{5}}}{k^{\frac{4}{5}}} \cdot\left(\frac{H_{S}^{2} \cdot K_{r}^{2} \cdot T}{8 \pi}\right)^{\frac{2}{5}}
$$

From here, the height at breaking, $H_{b}$, (Equation 19) is calculated, which is used as a NN input parameter.

$$
H_{b}=k \cdot d_{b}
$$

Shallow water significant wave height, $H_{s}$, is calculated by taking the significant wave height in deep water, $H_{o}$, times the shoaling coefficient, $K s$, and the refraction coefficient, $K r$. In order to calculate the mean energy of the wave climate, we use the root mean square (RMS) wave height, $H_{r m s}$, which is determined by a Rayleigh distribution and is known to be equal the significant wave height $\left(H_{s}\right)$ divided by the square root of two. Beach volumes change as sediments are transported by onshore wave energy. Below are velocity and energy equations for processes that are known to transfer sediments; therefore, they are included as inputs to the Neural Network. The calculation for onshore RMS wave energy flux, $E_{f b}$, a parameter used in the Neural Network, is shown in Equation 20. Here $\rho$ represents average sea water density $\left(1025 \mathrm{~kg} / \mathrm{m}^{2}\right)$ and $g$ denotes acceleration due to gravity $\left(9.81 \mathrm{~m} / \mathrm{s}^{2}\right)$

$$
E_{f b}=0.125 \cdot \rho \cdot g \cdot H_{r m s}^{2} \cdot C_{g} \cdot \cos \left(\theta_{s}-155^{o}\right)^{2}
$$

Equation 21 shows the longshore energy flux factor, $E_{L}$, needed for both longshore current and longshore transport calculations. Longshore current, $V_{b}$, the current that moves parallel to shore, is found algebraically using Equation 22.

$$
\begin{aligned}
& E_{L}=0.5 \cdot \sqrt{g * H_{r m s}} \cdot \sin \left(2 \cdot\left(\theta_{s}-155\right)\right) \\
& V_{b}=0.585 \cdot \sqrt{g * H_{r m s}} \cdot \sin \left(2 \cdot\left(\theta_{s}-155\right)\right)
\end{aligned}
$$


The amount of sediment transported due to the longshore current, or the process which carries sediment along the coastline, is called longshore transport, $Q b$. This process is numerically represented in Equation 23. This equation incorporates the longshore current parameter from the CEM, $K_{\text {sed }}$, as well as the sediment concentration in water, $A_{\text {sed. }}$ Again, 2.59 is the unitless specific density of quartz sand with respect to seawater and 0.8 is the mild slope.

$$
Q b=K_{\text {sed }} \cdot 0.125 \cdot \rho \cdot g \cdot H_{r m s}^{2} \cdot \frac{E_{f b}}{\rho \cdot(2.59-1)} \cdot g \cdot A_{s e d} \cdot \sqrt{.8}
$$

Bottom particle velocity, $u_{b}$, is the velocity of a particle in an ocean wave; this velocity is calculated using the Equation 24.

$$
u_{b}=\frac{g \cdot H_{b}}{C_{b} \cdot 2} \cdot \frac{1}{\cos \left(k_{\#} \cdot d_{b}\right)}
$$

Finally, the shields parameter, $\psi$, is calculated to determine the initiation of sediment movement in a fluid flow. This parameter is a non-dimensional expression of a shear stress. In order to find the shields parameter, total bottom velocity, $u T$, and bottom friction coefficient, $f_{b}$, are needed. Equation 25 outlines the calculation for undertow velocity, $U_{T B}$, a variable needed for finding total bottom velocity.

$$
U_{T B}=\frac{0.125 \cdot \rho \cdot g \cdot H_{r m s}^{2}}{\rho \cdot C} \cdot\left(h_{b}-0.5 \cdot H_{R M S}\right)
$$

Equation 26 is the calculation for total bottom velocity:

$$
u_{T}=\left(u_{b}+U_{T B}\right)^{2}
$$

In order to find the bottom friction coefficients, a Matlab function (friction) is used that incorporates the mean sediment size of EST-1 $(0.44 \mathrm{~mm})$ and wave bottom particle excursion length (Grilli, 2000). Therefore, the equation for the shields parameter, $\psi$, is (Equation 27): 


$$
\psi=0.5 \cdot u_{T} \cdot \frac{f}{(2.59-1) \cdot g \cdot 0.44}
$$

To summarize the above methodology, Table 3 lists all the wave parameters that have been calculated (rows 3-15). Not all of the variable calculations above are included in the Neural Network, although all of the above equations are needed to calculate the inputs used. In order to reduce the number of unknown weighting coefficients and develop an effective Neural Network, the parameters that correlate highly to each other are not included (Table 3). For example, total bottom velocity and undertow velocity, whose correlation coefficient is 0.96 , should not both be included as input parameters.

\section{$\underline{\text { Neural Network Design }}$}

The Neural Network is trained based on parameters and settings selected within the Neural Network Toolbox for Matlab. The Dynamic Time series application is used. Because the goal of the study is to predict beach volume, $y(t)$, using past values of the beach volume times-series as well as wave, NAO, and sea level data, a Nonlinear Autoregressive with External Inputs (NARX) network is chosen. This network uses the following function:

$$
y(t)=f(y(t-1), \ldots, y(t-d), x(t-1), \ldots,(t-d))
$$

In this equation, $y(t)$ is the beach volume time-series that is being predicted using $d$ past values of that time-series and past values of an additional time-series dataset, $x(t)$, which includes wave parameters, NAO, and sea level. A visual schematic of this feed forward network is shown in Figure 5. This schematic represents a multi-layer NN that has a continuous derivative that allows for backpropagation (discussed in next paragraph). The NN consists of an input layer, an output layer, and hidden layers 
between them. The number of hidden layers and time delays, $d$, is often determined by trial and error (Hashemi et al., 2010). For this work, 10 hidden layers and 2 timestep delays produced desirable results. Hidden neurons within the network give output values and weights to other neurons using connection weights and a transfer function, in this case a sigmoid function, where $\mathrm{x}$ is equal to the net input (Nestorov et al., 1999):

$$
\text { Neuron Output }=\frac{1}{1+e^{x}}
$$

Once the geometry of the network is determined, the connection weights between neurons are corrected for using the "learning" algorithm called backpropagation. The error between the predicted values and the target values are calculated. This error is then communicated through the network to adjust weights by considering the node input values, as well as the learning rate and momentum of the NN (speed of the training process) (Nestorov et al., 1999).

The NN development occurs in three stages: training, validation, and testing. For this study, the data was separated into the standard ratio of $70 \%$ for training, $15 \%$ for validation, and $15 \%$ for testing. The training step is the process of correcting the neuron connect weights. The validation data is used to determine when to stop adjusting the network. Finally, the testing is the predictive aspect of the NN - the network is run without adjustments to produce the final output layer. The outputs are compared to the target values using mean square error (MSE) and regression R values. The mean square error is the average squared difference of output and targets; lower values are desirable. Correlation between targets and the outputs is represented by the R values 0 to 1 , where 1 signifies a close relationship. 
Evaluating Variance of Targets Predictable by Inputs

Once a trained NN produces desired MSE and R values, the network is saved. New input parameters and/or new outputs can then be run through the trained network. This approach allows for testing of the network on different southern RI beaches, to test the repeatability of the model in different geologic locations. Additionally, input parameters can be removed or added. Through this iterative approach, the degree to which inputs predict the variance in beach volume for this particular NN can be determined by calculating the $\mathrm{R}^{2}$, a statistical measure of how closely the output data fit the target volume values. 


\section{Results}

Beach profile interpolations and volume time-series were created for each beach. All beach survey volume time-series can be found in Figure 6. Trends can be visually observed in the volume plots. MST and GRH beaches both have an overall decreasing trend with some increase in volume in the last 5 or so years. Other beaches, such as EST-2 and MIS, have volumes that seem to oscillate every 10-15 years. The beach volume for CHA-TB and EST-1 seem to have a trend of increasing or decreasing that might span almost 25 years, although with the current length of the dataset it is difficult to determine. WKG has the most visually variable trend with

frequent and at times large volume changes. To see if these beaches have any kind of linear relationship in sediment transport, correlation coefficients were calculated between each beach (Table 4). The beaches that have the highest linear relationship are MST and GRH. MST and MIS are on either end of the south shore, and these have the weakest correlation.

\section{$\underline{\text { EOF Analysis }}$}

As mentioned in Section 2, EOF analysis was run on each beach with respect to the corresponding mean profile. When the EOF analysis was run on the interpolated profiles (without respect to the mean) the first eigenfunction, which accounts for the most variance ( $>79 \%$ ), was closely related to the mean beach profile. This result left little variance to be accounted for through additional eigenfunctions. An example of this close eigenfunction match to the mean profile is shown for MST in Figure 7. For this aforementioned reason, the EOF analysis was instead run with respect to the mean profile. Figure 8 shows all of the seven mean 
profiles plotted on the same scale to show variations in slope and features. All of the beaches have overall slopes (from dune to swashzone) that range from -0.11 to -0.17 , calculated by finding the best linear fit for each profile (Table 5). Misquamicut has the steepest overall mean profile (-0.17). And although EST-1 has the steepest dune, the overall slope for the best linear fit (dune to swashzone) is the flattest $(-0.11)$.

Once all beach profiles for all beaches were demeaned the eigenfunction analysis was run. For all beaches, over $90 \%$ of profile variance is described in three to four eigenfunctions. The EOF analysis resulted in three eigenfunctions for MST and GRH which account for $95 \%$ and $98 \%$ variance, respectively. $94 \%$ of variance can be described in four eigenfunctions for CHA-TB. Both EST-1 and WKG have $96 \%$ of their variance described by four eigenfunctions. Similarly, $95 \%$ of the variance for EST-2 and MIS profiles in time can be described by four eigenfunctions. These eigenfunctions vary in shape across the profiles for each beach (Figure 9).

The resulting first eigenfunction for all demeaned beach profiles has a strong linear correlation between the coefficients and beach volume $\left(\mathrm{R}^{2}>0.96\right.$, beach depending). This correlation was either positive or negative (Table 6). If the correlation was negative, the first eigenfunction coefficients in time were a reflection of the volume time-series for that beach over the $\mathrm{x}$-axis. If the correlation was positive, the trends of the first eigenfunction coefficients in time matched the beach volume.

The remaining eigenfunctions describe changes in shape across the profile due to erosion and accretion throughout time. In order to understand when these patterns occur, the eigenfunction coefficients are examined. When the coefficients are 
positive, the peaks in the eigenfunctions indicate accretion in that region of the profile, while troughs show erosion. When the coefficients are negative, peaks in the eigenfunctions indicate erosion and troughs display accretion. In Table 7, these peaks and troughs are qualified in geologic terms across the beach profile for when all eigenfunction coefficients are positive. In this table the foredune (well-developed dune) and incipient dune (shoreward of the dune, less developed but vegetated) are closest to the $\mathrm{R}_{0}$ stake while the swashzone denotes the most shoreward area (Figure 3). Here, the patterns of erosion and accretion across profiles often differ between beaches. However, the second eigenfunction consistently has strong positive peaks and strong negative troughs in the foredune and berm locations, indicating that there is either landward accretion or shoreward erosion, beach depending. For example, when the coefficients of the second eigenfucntion are positive, MIS has a strong negative peak toward the foredune and incipient dune and a strong peak in the berm and swashzone portion of its profile, indicating that when the second eigenfunction coefficients are positive, there is erosion of the dune system and deposition on the berm and swashzone (Figure 10). The reflection of that trend is seen in CHA-TB, indicating that when the second eigenfunction cofficients are positive, there is sediment deposition in the dune portion of the profile. The third eigenfunction tends to have a peak or a trough directly in the berm location, representing either accretion or erosion of the berm, respectively, when the third coefficient is positive. When present, four eigenfunctions have peaks or troughs at every geologic zone across the profile. The dune and incipient dune for all beaches, except EST-1, sees the most variance across the cross-sectional profile; peaks and troughs are usually largest 
landward and the functions then come close to zero (no variation to mean profile) toward the swashzone. Although there are some similarities in the erosion and accretion patterns between beaches, the eigenfunctions between beaches differ in their percent contribution to the overall variance, the strength of the troughs and peaks, and their shape.

Dominant cycles in these eigenfunction coefficients are determined through power spectrum density plots and corresponding significant frequency values for EST1, EST-2, and MIS due to the likelihood that cycles could be obtained from these beaches, as discussed in Section 1: Introduction. Figures 11-13 display the power spectrums for these beaches. In each of these beaches, every coefficient's most powerful spectral peak was in a range from 0.0451 to 0.0469 ; corresponding to a periodicity of about 21-22 years. An additional significant frequency ranging from 0.12 to 0.18 is present between coefficients; indicative of a $\sim 5-8$ year periodicity. Lastly, in most of these beach profile eigenfunction coefficients, a frequency spectrum peak in the range of $0.98-1.125$ is present, corresponding to an annual periodicity.

\section{Neural Network}

A neural network was developed using the previously discussed eleven input parameters (Table 3) with EST-1 beach volume in time as the target. As discussed in Section 2, the NN was first trained on $70 \%$ of the data (294 time steps), validated on $15 \%$ (63 time steps), and finally tested on 15\% (63 time steps). These steps are performed randomly throughout the time steps in order to structure a prediction algorithm that is not time dependent. The training, validation, and testing outputs had a strong linear correlation to the target values $(\mathrm{R}=0.901,0.881$, and 0.823 , 
respectively) (Figure 14). For each of these steps, the mean squared error (MSE) was also calculated for training, validation, and testing (MSE $=171,210$, and 285 respectively). MSE is desired to be low as it is the average squared difference between output and targets. NN responses during these development stages are visually represented in Figure 15. This figure shows where the NN was able to accurately predict beach volume within the time-series using the inputs supplied as well as where it had higher error. There are not prominant trends along the time-series for frequency or degree of error. Figure 16 shows an error (targets minus outputs) histogram. In testing, errors seem to be more positive than negative; meaning that the $\mathrm{NN}$ often underestimates the volume.

The NN was then saved and the entire dataset (all 420 time steps) was used in the final testing stage. This final analysis resulted in a lower MSE (195) and a higher linear correlation between outputs and targets $(R=0.886)$ than just testing the network on $15 \%$ of the time steps. Relying on the geometric structure of the developed network, the selected input parameters were able to account for about $79 \%$ of the variance in beach volume $\left(\mathrm{R}^{2}=0.785\right)$. The output values from the $\mathrm{NN}$ testing using the entire time-series were plotted against the target values in Figure 17.

The same NN created for EST-1 was tested on the two surrounding beaches, EST-2 and MIS, to compare to effectiveness of the NN to model and predict volume at a different location. The same input parameters were used that were calculated for EST-1. The resulting R for both EST-2 and MIS beaches as targets was much lower; EST-2 had an R value of 0.4722 and MIS a linear correlation of $\mathrm{R}=0.3077$. The MSE for these different targets were also high: EST-2 as target volume was 540 while 
MIS was 429. A summary of the above results, EST-1 as a target as well as EST-2 and MIS targets, can be found in Table 8.

The saved NN relies on the design and structure of the original conditions. A limitation recognized in this exercise is that input variables cannot simply be removed from the set of inputs to understand their contribution to the variance in beach volume; this NN will not run without eleven input parameters. Therefore, assessing the variance of the targets that are predictable by certain inputs is beyond the scope of this project at this time. 


\section{Discussion}

The eigenfunction analysis and the neural network methodologies prove that there are different physical forcings, and/or a different degree of these forcings, between all of the southern Rhode Island beaches. However, there were some similarities between beaches depicted through the eigenfunction analysis. Over $90 \%$ of beach variation with respect to the mean profile in the cross-shore direction was able to be explained by 3-4 eigenfunctions for all beaches. This quantity of eigenfunctions to describe a high percentage of beach change is consistent with existing studies involving beach morphology using these methods (Mangus Larson \& Kraus, 1994; Winant et al., 1975). The eigenfunction shapes show increases and decreases in elevation across the profile that allow for interpretation of erosion and accretion patterns. The following text will discuss the similarities and differences in eigenfunction shapes and spectral analyses between EST-1, EST-2, and MIS. The first eigenfunction, when EOF analysis is run on profiles that have not been demeaned, is closely related to the mean profile. Nearly all studies using eigenfunciton analysis to study beach change recover the "mean profile" function as the first eigenfunction (Karunarathna et al., 2016; Mangus Larson \& Kraus, 1994; Winant et al., 1975; and others). In this work, after demeaning the data, the weighted coefficients of the first eigenfunction are related to beach volume, in a positive or negative correlation (Table 6). The eigenfunctions for most beaches show that most of the variance is seen at the dune and incident dune, some is seen at the berm, and the least significant changes are seen near the swash zone. This pattern means that the most sediment variations are seen landward through erosion and accretion processes. It also signifies that wind strength/direction as well 
as storm surge and wave height likely play a key role in beach morphology along the southern shore of Rhode Island.

The second eigenfunction in this study is the erosion/accretion of the dune and berm structures; this eigenfunction is interpreted to resemble sediment transport on and off-shore. The third eigenfunction has peaks and troughs located just at the berm of these beaches. The third coefficients for EST-1 and MIS oscillate around zero, but in EST-2 the coefficients are decreasing over time; indicating that the berm at EST-2 has been eroding with time. Evidence of this erosion can be seen in field observations as well as comparisons of past and present profiles. The fourth eigenfunction (when present) is attributed to smaller scale erosional patterns that deform the mean profile. These findings are similar to those reported by Karunarathna et al., 2016.

The most powerful spectral peaks in eigenfunction weighted coefficients across these three beaches (1/0.0451 and 1/0.0469 year) corresponds to a 21 to 22 -year periodicity. The uniqueness in this survey length and the ability to recover this wavelength cycle makes it difficult to determine what the cause of this frequency peak might be. This multidecadal cycle could be attributed to mean sea levels in the area. Multitaper method (MTM) spectral analysis was run on 61 years of Newport, RI tide gauge data (1965-2017) and there was a significant cyclicity of about 22 years (frequency: 0.046) in this data (Figure 18). Additionally, the Hale solar cycle does have a periodicity of 11 and 22 years. We hypothesize that these periods of increased solar radiation and changes in sunspots could potentially cause increased wave action and/or changes in intensities of ENSO events (Goy, Zazo, \& Dabrio, 2003; 
Landscheidt, 2000), therefore altering the coast. With additional years of data, this 21 to 22-year cyclicity within the beach survey dataset will be more fine-tuned.

Although the sediment transport patterns differ between beaches, significant spectral peaks for the coefficients of the second eigenfunction are consistently seen at about 5-8 years for EST-1 and MIS. This peak could correspond to the periodicity of NAO climatic variability or some function of the longshore transport that Lacy and Peck (1999) recovered. Spectral analysis (MTM) was run on the monthly NAO index from Hurrell et al. 2017 (Figure 18). A significant spectral peak was recovered of 0.12 , corresponding to an 8-year periodicity. EST-1 also has a significant peak at 1 year for this second eigenfunction; this beach often sees a dramatic summer-winter berm profile throughout the year that could correspond to this annual periodicity in the dune-berm function.

Although there are similarities in the spectral analyses between these beaches, the eigenfunction's shapes, strengths of peaks and troughs, and the percent contribution to the overall variance are vastly different. Therefore, sediment transportation patterns in the cross-profile direction are likely driven by different processes and forcings. Determining relationships between these factors are important for predicting, mitigating, and recovering from major alterations in beach morphology. The results presented here indicate potential ties between climatic events and sea level forcings to RI beach morphology change.

The NN was a successful method for modeling and predicting beach volume. The input parameters chosen and the NN's autocorrelation function were able to account for about $78 \%$ of variance in volume change at EST-1. A MSE value of 194 for 
testing the network indicates that it is able to, on average, estimate the beach volume using the input parameters within about $13 \mathrm{~m}^{3} / \mathrm{m}$. This model proves that $\mathrm{NN}$ can be used as a predictive measure of EST-1 beach volume. Successful models such as these could also be used to estimate sediment recovery times after large storms or other natural and man-made causes.

The NN created for EST-1 was not transferable to predict beach volumes for other beaches. This finding builds upon the results of the EOF analysis - the forcings that contribute to beach variance are different across the spatial area of the southern RI coast. Wave parameters were calculated to resemble the local wave climate for EST-1. The hard structures (man-made and geological) and bathymetric differences between these beaches surely alter the local wave climate. For example, MST and GRH are located close to a glacial headland where there is wave focusing. These beaches are also west of the Point Judith Harbor Refuge; where a system of jetties protect the harbor. These man-made hard structures may alter the direction of circulation and longshore current for MST and GRH. For beaches located on the far western side of the coast, there is a shallowing of bathymetry between Block Island and Long Island that likely filters wave action by depth. Lastly, beaches positioned behind the north coast of Block Island are protected from some wave activity and wind from the south due to sheltering effects.

Understanding what sediment is available offshore would greatly improve the eigenfunction analysis and development of a NN for this dataset. Incorporating bathymetric surveys to these onshore profiles would allow for understanding of sediment transport based on sediment pools offshore and therefore sediment 
availability. The University of Rhode Island's beach survey is beginning to incorporate bathymetric surveying that is simultaneously collected with LiDAR data to measure seamless topo-bathymetry changes (preliminary procedural documents for processing LiDAR are included in the Appendix. Additionally, the development of the primary and incipient dunes are strongly linked to vegetation (Masselink, Hughes, \& Knight, 2011). Including the vegetation cover on the dune is a NN input parameter that should be investigated.

In time-series analysis, NNs are most commonly used to model and predict desired target values. Although this study produced convincing results for the predictive proficiency of NNs for beach volume, the explanatory capabilities of the input parameters are not yet understood. Because this study was unable to simply remove input parameters and rerun the $\mathrm{NN}$, the weight that one input parameter has on the predictably of the NN cannot be determined. In our model it is not possible to know how much the NAO index verses significant wave height contributes to the model's success. Future work should explore methodologies of extracting the percent contribution to the variance of each input parameter. Gevrey, Dimopoulos, \& Lek (2003) explored seven different methods for testing input parameters and their impacts on variance predictability. These methods, along with additional statistical model creation, such as a SARIMAX (seasonal autoregressive integrated moving average) model should be considered and compared to NN. This type of regression model can determine parameter contribution to the variance by adding the parameters as covariates to an already established regression model. 


\section{Conclusions}

Eigenfunction analysis proved to be a successful method in assessing cross-shore beach change both spatially across the profile and temporally. Resulting spectral analysis of eigenfunction weighted coefficients show profile change periodicities at about 1 year, 3-4 years, 5 years, and 21 years. Although similar temporal cycles within the eigenfunction coefficients were found, the shapes and spatial patterns of the eigenfunctions were not uniform between beaches. This work demonstrates that climatic forcings such as NAO and sea level likely influence coastal geomorphology. A Neural Network was developed for beach volume of EST-1 using wave parameters derived from offshore hindcast data transformed to model nearshore conditions along with the NAO index and monthly MSL as input parameters. Resulting statistical calculations $(\mathrm{MSE}=194$ and $\mathrm{R}=0.886)$ confirm the NN's effectiveness in modeling output values to closely match desired targets. The chosen input parameters used in the NN were able to predict $78 \%$ of variance in beach volume change through time. This model did not perform well with different beach volumes as targets. Results from both eigenfunction analysis and the development of a NN have determined that the forcings that control or contribute to profile change differ greatly across the southern shore. 
Table 1. Location and elevation changes of $\mathrm{R}_{0}$ stake for each beach. The profile number is the number of profiles that had occurred at the beach at that date.

\begin{tabular}{|c|c|c|c|c|c|c|}
\hline Profile Site & Profile Number & Date & R0 (rispf Easting) & R0 (rispf Northing) & R0 (m NAVD88) & Azimuth \\
\hline \multirow{6}{*}{ MST } & 1 & $12 / 19 / 62$ & 307140.07 & 104537.99 & 3.3558 & 161.157 \\
\hline & 293 & $07 / 14 / 78$ & 307140.07 & 104537.99 & 3.5387 & 161.157 \\
\hline & 323 & $12 / 19 / 79$ & 307140.07 & 104537.99 & 3.9654 & 161.157 \\
\hline & 337 & $08 / 21 / 80$ & 307140.07 & 104537.99 & 3.5387 & 161.157 \\
\hline & 338 & $09 / 04 / 80$ & 307140.07 & 104537.99 & 3.9654 & 161.157 \\
\hline & 544 & $01 / 06 / 93$ & 307131.35 & 104563.54 & 3.3455 & 161.157 \\
\hline \multirow{7}{*}{ GRH } & 1 & $12 / 19 / 62$ & 298717.17 & 102312.01 & 2.9883 & 178.388 \\
\hline & 201 & $09 / 28 / 72$ & 298717.11 & 102314.01 & 2.9883 & 178.388 \\
\hline & 558 & $12 / 07 / 92$ & 298716.38 & 102340.00 & 2.4582 & 178.388 \\
\hline & 675 & $04 / 30 / 99$ & 298716.70 & 102328.52 & 2.7783 & 178.388 \\
\hline & 705 & $12 / 27 / 00$ & 298716.38 & 102340.00 & 2.4582 & 178.388 \\
\hline & 806 & $04 / 17 / 07$ & 298702.58 & 102361.89 & 2.4582 & 178.388 \\
\hline & 913 & $11 / 09 / 12$ & 298708.34 & 102394.78 & 2.4430 & 178.388 \\
\hline \multirow{3}{*}{ СНA-TB } & 1 & $111 / 20 / 75$ & 293417.45 & 101216.57 & 3.9752 & 160.649 \\
\hline & 101 & $09 / 04 / 80$ & 293417.45 & 101216.57 & 4.3105 & 160.649 \\
\hline & 673 & $11 / 09 / 12$ & 293413.44 & 101225.25 & 3.9310 & 160.649 \\
\hline \multirow{4}{*}{ EST-1 } & 1 & $12 / 19 / 62$ & 277202.96 & 95268.140 & 3.2059 & 155.149 \\
\hline & 301 & $07 / 14 / 78$ & 277195.31 & 95284.655 & 3.4558 & 155.149 \\
\hline & 424 & $10 / 10 / 85$ & 277188.42 & 95299.54 & 2.9560 & 155.149 \\
\hline & 901 & $12 / 07 / 12$ & 277187.71 & 95299.43 & 3.2350 & 155.149 \\
\hline \multirow{7}{*}{ EST-2 } & 1 & $08 / 20 / 76$ & 284679.39 & 97998.41 & 2.6688 & 153.182 \\
\hline & 6 & $11 / 05 / 76$ & 284690.31 & 97976.82 & 4.3300 & 153.182 \\
\hline & 157 & $10 / 10 / 85$ & 284682.91 & 97991.46 & 3.9600 & 153.182 \\
\hline & 283 & $12 / 07 / 92$ & 284662.82 & 98031.19 & 3.9600 & 153.182 \\
\hline & 446 & $11 / 07 / 03$ & 281551.16 & 96910.06 & 2.6408 & 157.963 \\
\hline & 456 & $09 / 26 / 04$ & 284662.82 & 98031.19 & 3.9600 & 153.182 \\
\hline & 587 & $01 / 29 / 13$ & 284662.33 & 98030.84 & 3.9750 & 153.182 \\
\hline \multirow{4}{*}{ WKG } & 1 & $212 / 19 / 62$ & 261528.77 & 89815.20 & 3.5272 & 161.415 \\
\hline & 204 & $12 / 06 / 72$ & 261528.29 & 89816.62 & 3.5272 & 161.415 \\
\hline & 844 & $12 / 18 / 08$ & 261528.29 & 89816.62 & 3.6302 & 161.415 \\
\hline & 915 & $11 / 09 / 12$ & 261519.13 & 89843.51 & 2.9090 & 161.415 \\
\hline \multirow{3}{*}{ MIS } & 1 & $07 / 26 / 77$ & 251547.43 & 89116.42 & 4.6287 & 169.169 \\
\hline & 454 & $09 / 18 / 02$ & 251542.50 & 89142.20 & 4.2187 & 169.169 \\
\hline & 638 & $11 / 09 / 12$ & 251542.34 & 89141.81 & 4.3700 & 169.169 \\
\hline
\end{tabular}

Table 2. Available quantity of profile data from each beach. Shown here are the number of raw profile time steps and number of subsequent bi-monthly profiles that were interpreted. Time steps and number of interpolated cross-sectional points varied due to hiatuses in surveying (due to weather, equipment functionality, etc.) and differing maximum observed distances from $\mathrm{R}_{0}$, respectively.

\begin{tabular}{|c|c|c|c|c|}
\hline Profile Site & $\begin{array}{c}\text { Number of Profiles Collected } \\
\text { (Time Steps) }\end{array}$ & $\begin{array}{c}\text { Maximum Observed Overall } \\
\text { Distance ( } \mathrm{x} \text {-direction) from Ro } \\
\text { (meters) }\end{array}$ & $\begin{array}{c}\text { Number of Interpelated (Every } \\
\text { 2m) Cross-Sectional Points }\end{array}$ & $\begin{array}{l}\text { Number of Interpolated } \\
\text { Bi-Monthly Profiles }\end{array}$ \\
\hline MIST & 952 & 76 & 39 & 1298 \\
\hline CHA-TB & 729 & 72 & 37 & 958 \\
\hline EST-1 & 958 & 80 & 41 & 1298 \\
\hline EST-2 & 618 & 76 & 39 & 962 \\
\hline WKG & 914 & 70 & 36 & 1193 \\
\hline
\end{tabular}




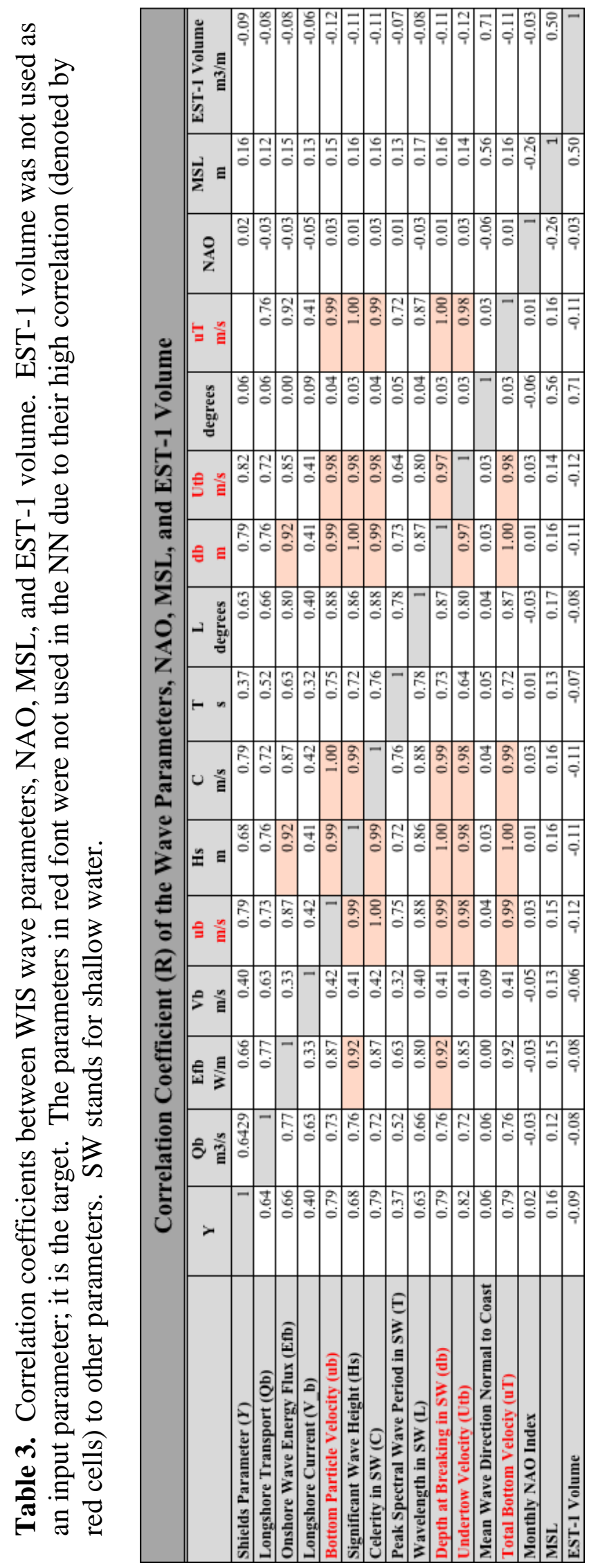




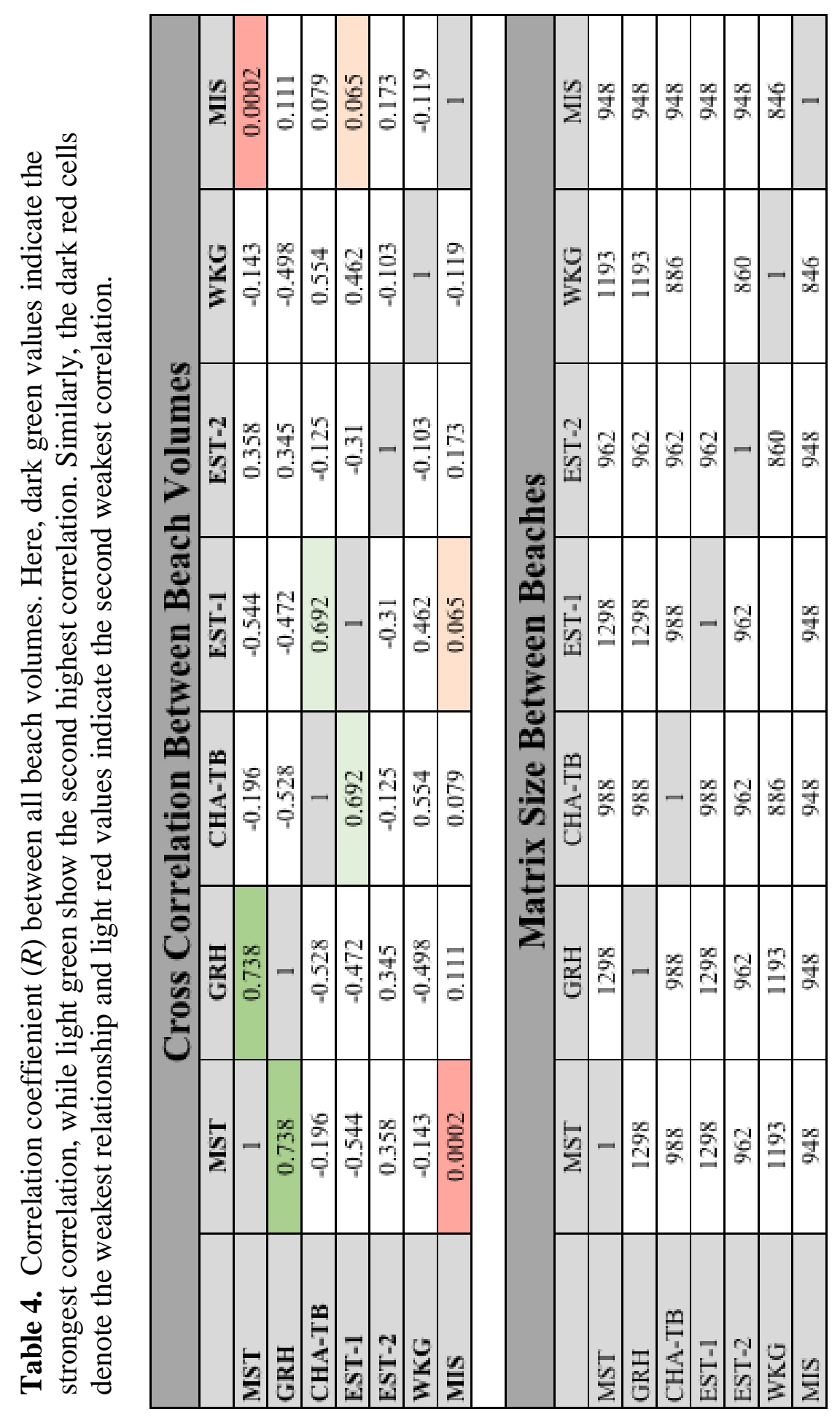


Table 5. Best fit equations for each mean beach profile. These best fit equations were determined for the entire length of the profile (dune to swashzone).

\begin{tabular}{|l|c|}
\hline \multicolumn{2}{|c|}{ Best Linear Fit for Each Mean Profile } \\
\hline & Linear Fit Equation \\
\hline MST & $\mathrm{y}=-0.12 \mathrm{x}+3.6$ \\
\hline GRH & $\mathrm{y}=-0.13 \mathrm{x}+3$ \\
\hline CHA-TB & $\mathrm{y}=-0.14 \mathrm{x}+4.3$ \\
\hline EST-1 & $\mathrm{y}=-0.11 \mathrm{x}+3.5$ \\
\hline EST-2 & $\mathrm{y}=-0.12 \mathrm{x}+3.3$ \\
\hline WKG & $\mathrm{y}=-0.14+4.9$ \\
\hline MIS & $\mathrm{y}=-0.17 \mathrm{x}+3.8$ \\
\hline
\end{tabular}

Table 6. Number of Eigenfunctions for each beach and the amount of variance in profile shape that each function explains. The total variance that all of the eigenfunctions account for for each beach is in the first column. The percent of the variance that each eigenfunction explains is included in the fourth column. Finally, the last column tells if the linear correlation between the second eigenfunction coefficients and beach volume was positive or negative. Under that text, the $\mathrm{R}^{2}$ value of that linear correlation is listed.

\begin{tabular}{|c|c|c|c|c|}
\hline & $\begin{array}{c}\text { Total \% } \\
\text { Variance }\end{array}$ & Num. EOF & $\%$ Variance & $\begin{array}{l}\text { 2nd EOF } \\
\text { Linear } \\
\text { Correlation } \\
\text { to Volume }\end{array}$ \\
\hline \multirow{3}{*}{ MST } & \multirow{3}{*}{95} & \multirow{3}{*}{3} & 81.62 & \multirow{3}{*}{$\begin{array}{c}\text { Positive } \\
0.9931\end{array}$} \\
\hline & & & 9.11 & \\
\hline & & & 4.11 & \\
\hline \multirow{3}{*}{ GRH } & \multirow{3}{*}{98} & \multirow{3}{*}{3} & 84.44 & \multirow{3}{*}{$\begin{array}{c}\text { Positive } \\
0.9989\end{array}$} \\
\hline & & & 8.65 & \\
\hline & & & 2.83 & \\
\hline \multirow{4}{*}{ СНА-ТВ } & \multirow{4}{*}{94} & \multirow{4}{*}{4} & 52.19 & \multirow{4}{*}{$\begin{array}{c}\text { Negative } \\
0.9746\end{array}$} \\
\hline & & & 23.01 & \\
\hline & & & 10.22 & \\
\hline & & & 5.85 & \\
\hline \multirow{4}{*}{ EST-1 } & \multirow{4}{*}{96} & \multirow{4}{*}{4} & 63.84 & \multirow{4}{*}{$\begin{array}{c}\text { Negative } \\
0.9896\end{array}$} \\
\hline & & & 13.53 & \\
\hline & & & 10.71 & \\
\hline & & & 5.45 & \\
\hline \multirow{4}{*}{ EST-2 } & \multirow{4}{*}{95} & \multirow{4}{*}{4} & 59.42 & \multirow{4}{*}{$\begin{array}{c}\text { Negative } \\
0.9766\end{array}$} \\
\hline & & & 16.36 & \\
\hline & & & 10.83 & \\
\hline & & & 6.61 & \\
\hline \multirow{4}{*}{ WKG } & \multirow{4}{*}{96} & \multirow{4}{*}{4} & 43.38 & \multirow{4}{*}{$\begin{array}{c}\text { Negative } \\
0.9852\end{array}$} \\
\hline & & & 36.29 & \\
\hline & & & 9.52 & \\
\hline & & & 5.37 & \\
\hline \multirow{4}{*}{ MIS } & \multirow{4}{*}{95} & \multirow{4}{*}{4} & 46.30 & \multirow{4}{*}{$\begin{array}{c}\text { Positive } \\
0.9698\end{array}$} \\
\hline & & & 32.25 & \\
\hline & & & 9.36 & \\
\hline & & & 4.32 & \\
\hline
\end{tabular}


Table 7. Simplified geologic interpretation of eigenfunction shape in a cross-shore beach profile. Red cells denote erosional patterns and green represents accretion along the dune, incipient dune, berm, and/or swashzone.

\begin{tabular}{|c|c|c|c|c|c|}
\hline \multicolumn{6}{|c|}{ Geologic Interpretation of Eigenfunction Shape Cross-Shore } \\
\hline & EOF & Dune & Incipient Dune & Berm & Swashzone \\
\hline \multirow{2}{*}{ MST } & 2 nd & Erosion & Accretion & Accretion & Accretion \\
\hline & $3 \mathrm{rd}$ & Erosion & Accretion & Erosion & Erosion \\
\hline \multirow{3}{*}{ GRH } & & & & & \\
\hline & $2 \mathrm{nd}$ & Accretion & Accretion & Erosion & Erosion \\
\hline & $3 \mathrm{rd}$ & Erosion & Accretion & Accretion & Erosion \\
\hline \multirow{3}{*}{ CHA-TB } & $2 \mathrm{nd}$ & Accretion & Accretion & Erosion & Erosion \\
\hline & 3 rd & Erosion & Erosion & Accretion & Erosion \\
\hline & 4 th & Erosion & Accretion & Erosion & Accretion \\
\hline \multirow{4}{*}{ EST-1 } & & & & & \\
\hline & 2nd & Erosion & Erosion & Accretion & Accretion \\
\hline & $3 \mathrm{rd}$ & Erosion & Erosion & Accretion & Erosion \\
\hline & 4 th & Accretion & Erosion & Accretion & Erosion \\
\hline \multirow{3}{*}{ EST-2 } & $2 n d$ & & Erosion & & Accretion \\
\hline & $3 \mathrm{rd}$ & Accretion & Erosion & Accretion & Accretion \\
\hline & 4 th & Accretion & Erosion & Accretion & Erosion \\
\hline \multirow{3}{*}{ WKG } & $2 n d$ & Erosion & Erosion & Accretion & Accretion \\
\hline & $3 \mathrm{rd}$ & Erosion & Accretion & Accretion & Erosion \\
\hline & 4 th & Erosion & Accretion & Erosion & Accretion \\
\hline \multirow{3}{*}{ MIS } & 2nd & Erosion & Erosion & Accretion & Accretion \\
\hline & $3 \mathrm{rd}$ & Accretion & Accretion & Erosion & Accretion \\
\hline & 4th & Accretion & Erosion & Accretion & Erosion \\
\hline
\end{tabular}

Table 8. Evaluation of MSE and R for training, validation, and testing of NN.

\begin{tabular}{|c|c|c|c|c|}
\hline \multicolumn{5}{|c|}{ Neural Network Training, Validation, and Testing Results } \\
\hline & & MSE & $\mathbf{R}$ & R Squared \\
\hline \multirow{4}{*}{ EST-1 } & Training $(70 \%)$ & 171 & 0.901 & 0.812 \\
\hline & Validation $(15 \%)$ & 210 & 0.881 & 0.777 \\
\hline & Testing (15\%) & 285 & 0.823 & 0.677 \\
\hline & Testing $(100 \%)$ & 194 & 0.886 & 0.785 \\
\hline$F$ & & 540 & & 023 \\
\hline MIS & \begin{tabular}{|l} 
Testing $(100 \%)$ \\
\end{tabular} & $\frac{3+0}{429}$ & 0.408 & 0.095 \\
\hline
\end{tabular}




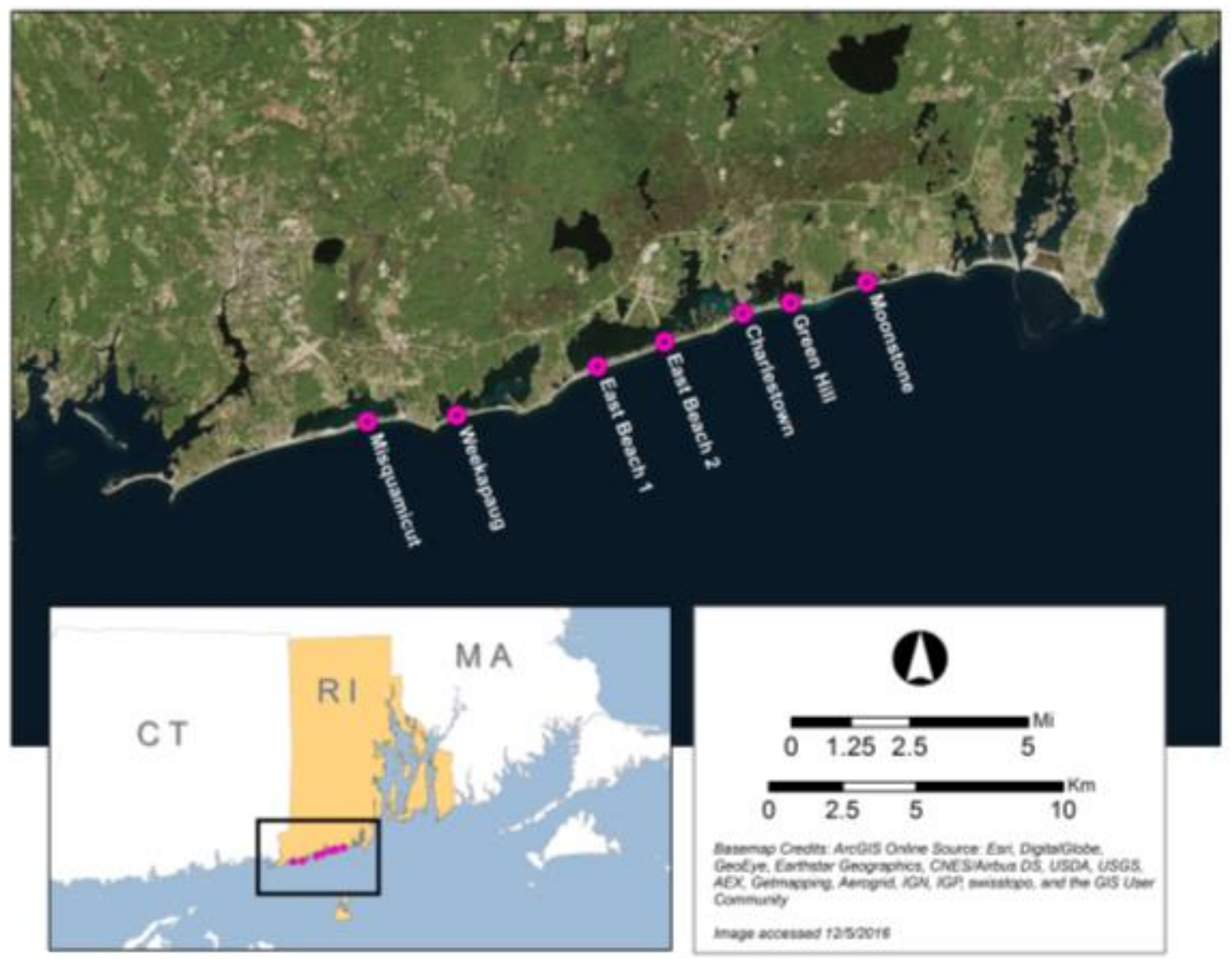

Figure 1. Location map of the seven continually surveyed beach profile locations. From west to east: Misquamicut (MIS), Weekapaug (WKG), East Beach 1 (EST-1), East Beach 2 (EST-2), Charlestown Town Beach (CHA-TB), Green Hill (GRH), and Moonstone (MST). Figure created by Carol Gibson in ArcGIS. 


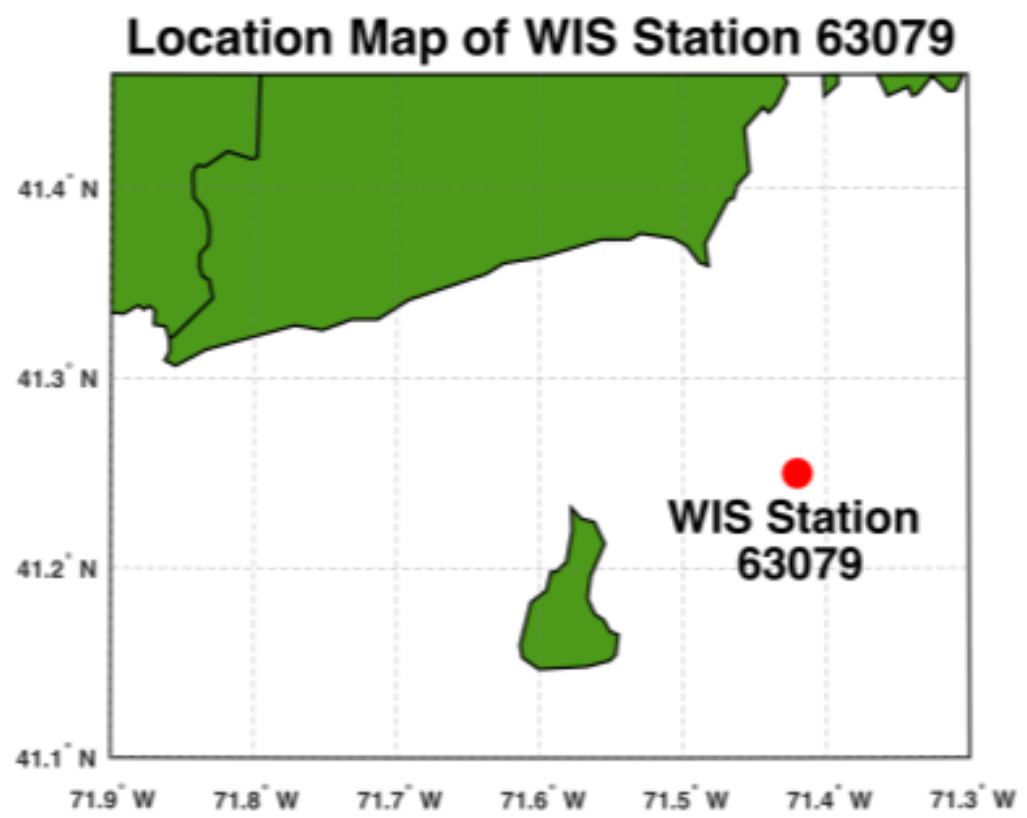

Figure 2. Location map of the Wave Information Studies (WIS) station 63079 where hindcast time series data was used to calculate nearshore wave parameters. This station is located at $41.25^{\circ}$ North and $71.42^{\circ}$ West, approximately 14 kilometers North East of Block Island, RI and 13 kilometers SE of Point Judith, RI. 


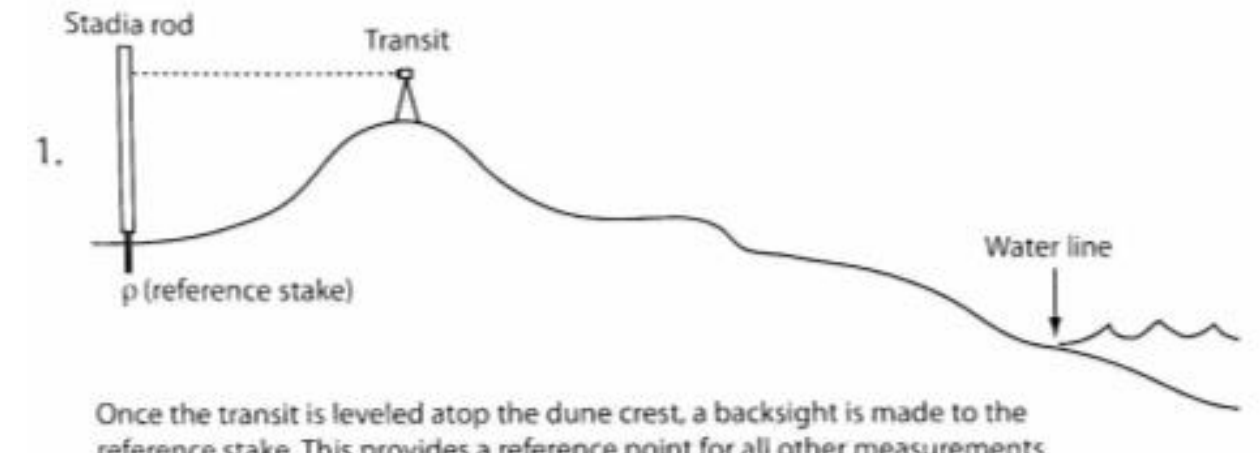
reference stake. This provides a reference point for all other measurements.

2.

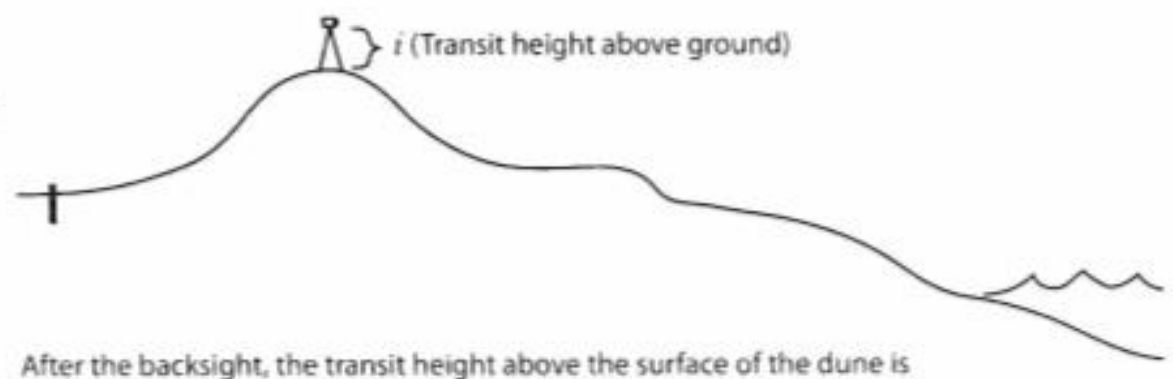
measured. This height is subtracted from all measurements in order to lower the values to ground elevation.

3.

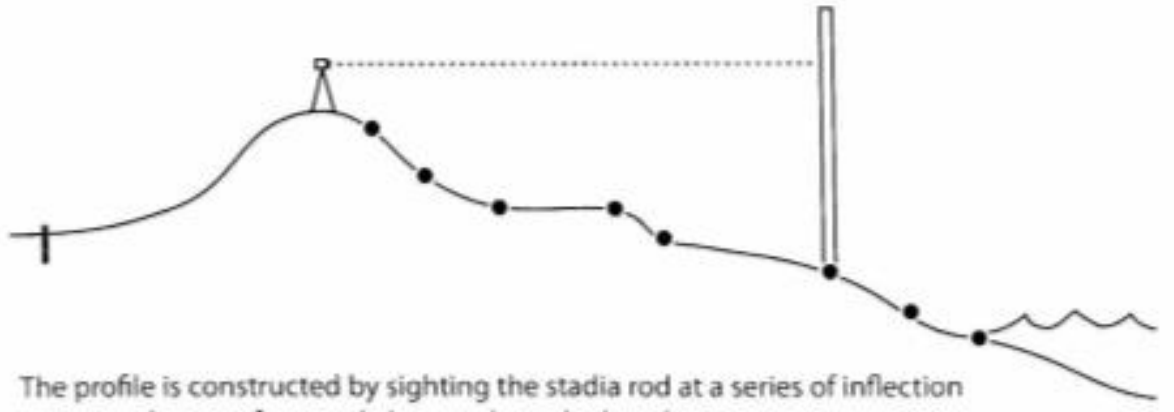
points and areas of textural change along the beach.

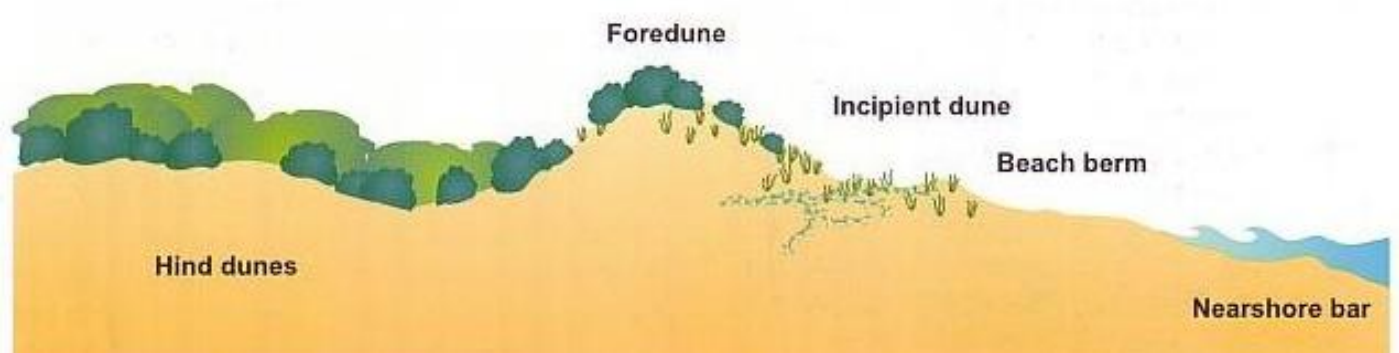

Figure 3. Above: This is a generalized diagram of the stadia-style profiling technique that has been used since the 1960s to monitor cross-sectional beach change for the seven southern RI beaches discussed in this work. This figure was modified from Peck, 1989 and taken from the Beach Survey report for 2008-2009 by Stephen G. Smith. Below: Visual schematic of common beach features. 


\section{WIS-79 wave data direction $\alpha_{\mathrm{o}}$ (deg.) 1980-2014}
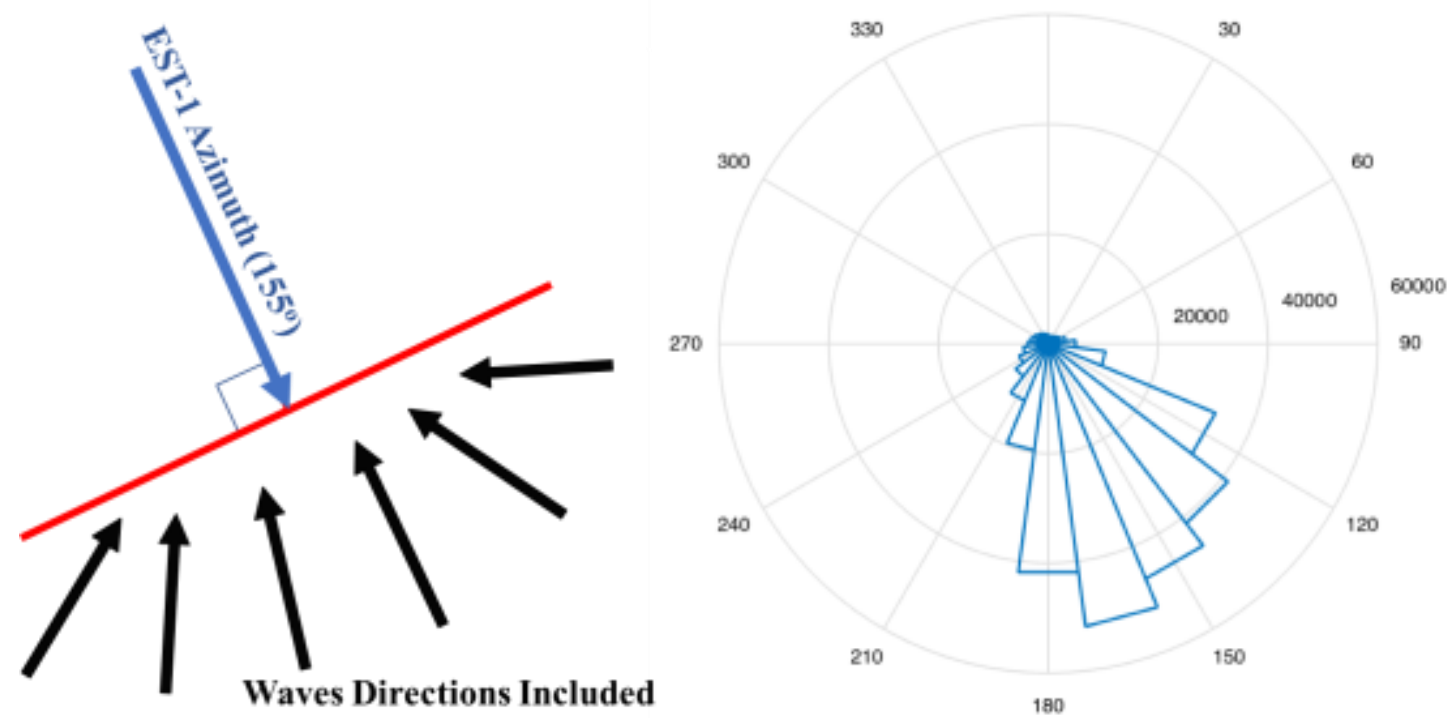

Figure 4. Wave rose created using WIS data for direction and amount of incident waves within $90^{\circ}+/$ - the EST-1's azimuth $\left(155.1^{\circ}\right)$. 


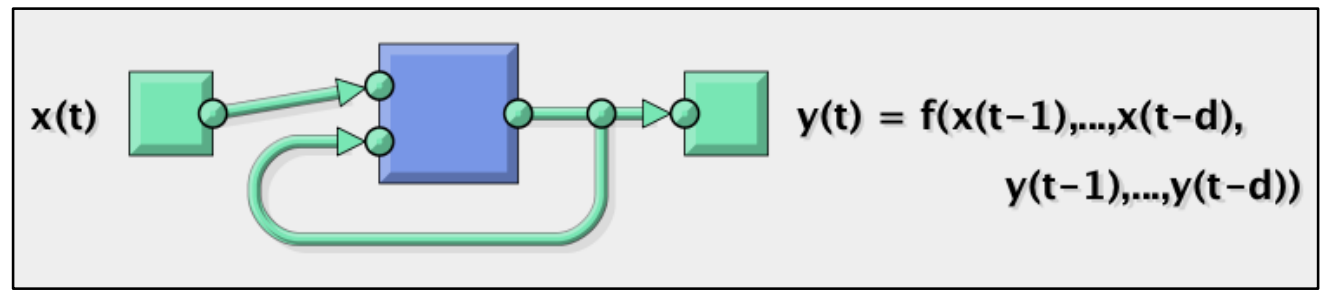

Figure 5. Visual schematic of a NARX model. Here, beach volume is predicted using $d$ past values of that time-series, $y(t)$, as well as past values of the input parameter time-series, $x(t)$. 

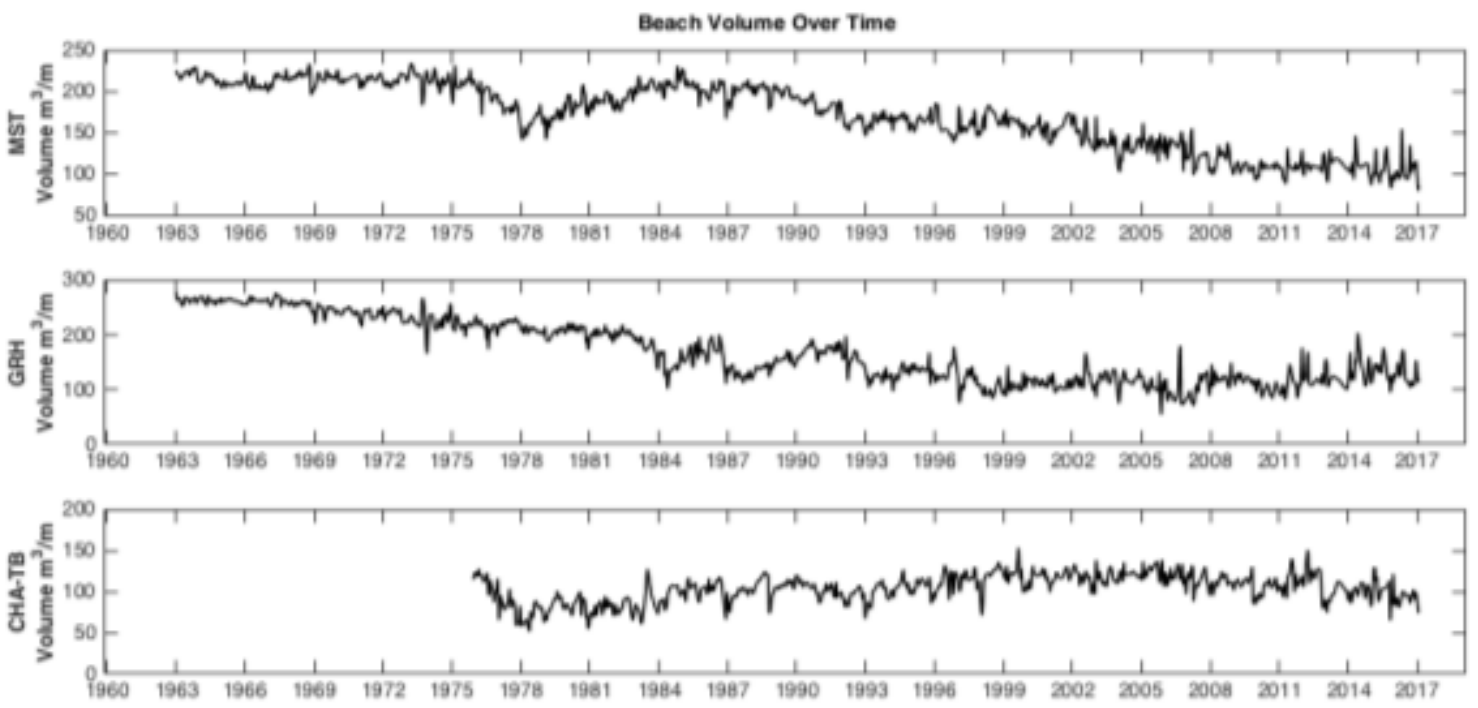

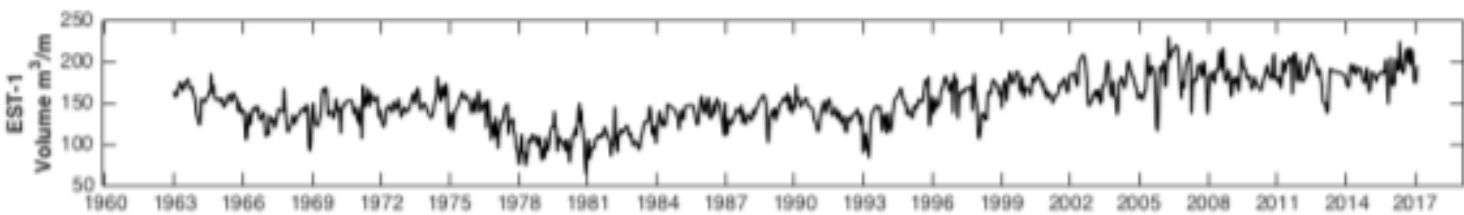
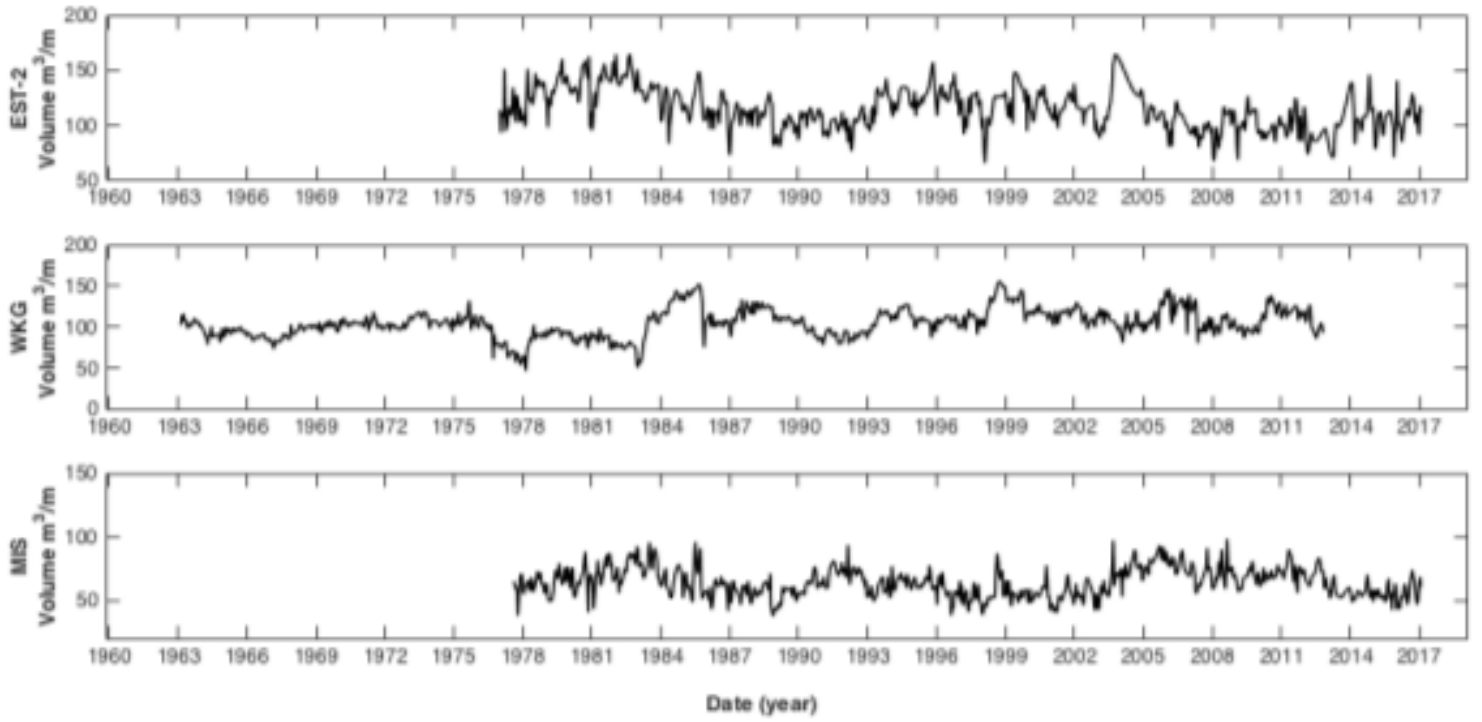

Figure 6. All southern Rhode Island profile-derived beach volumes plotted with time. 


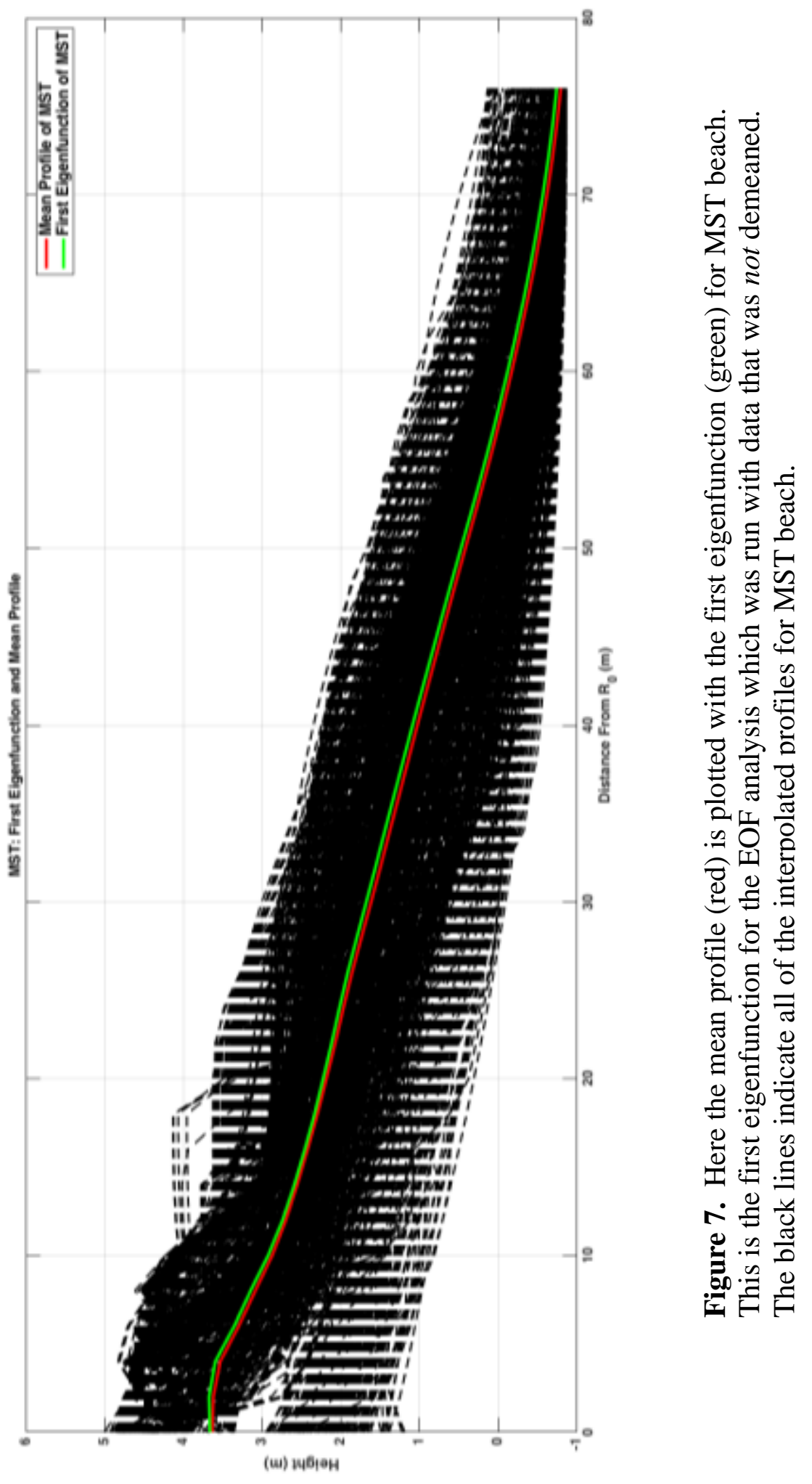




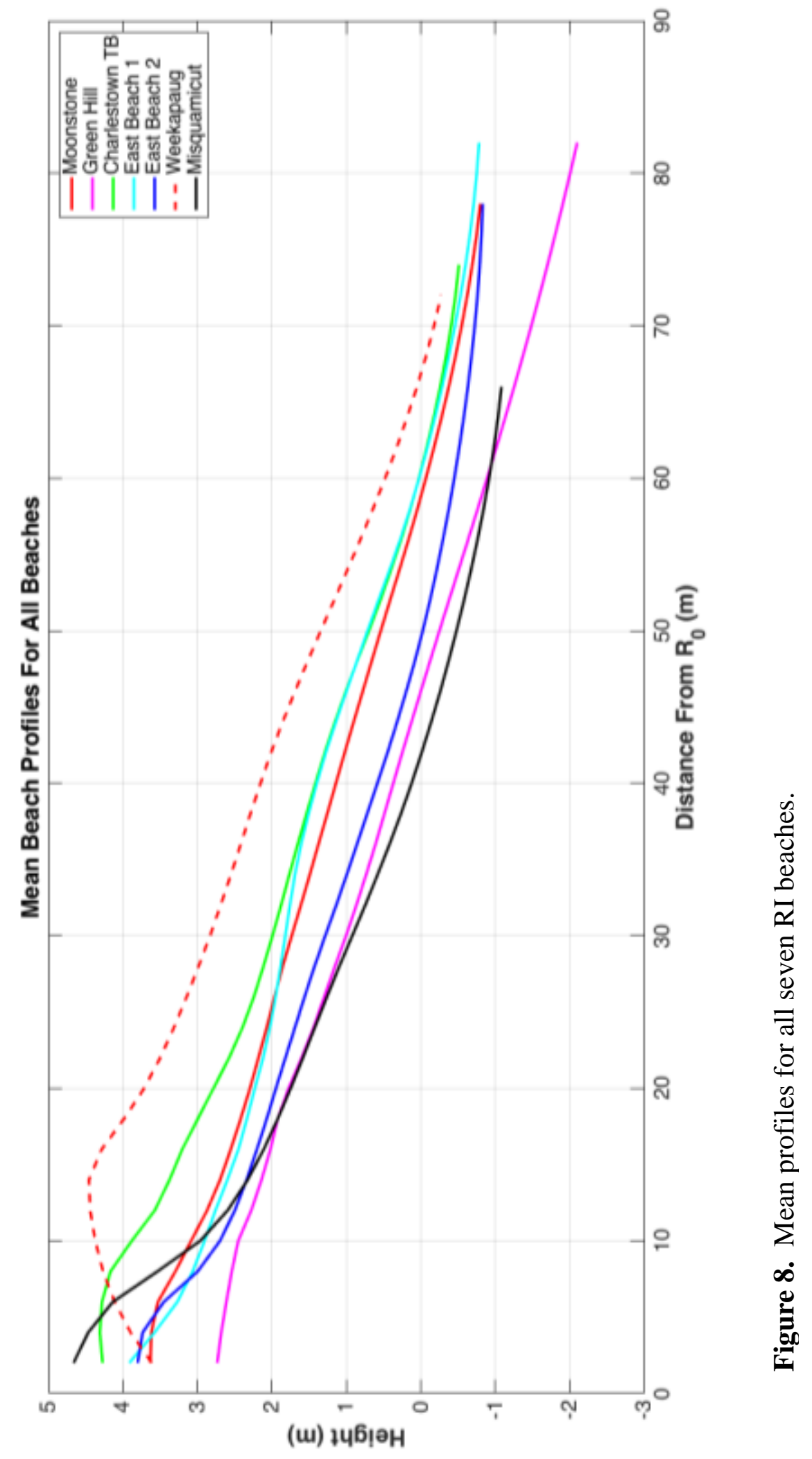



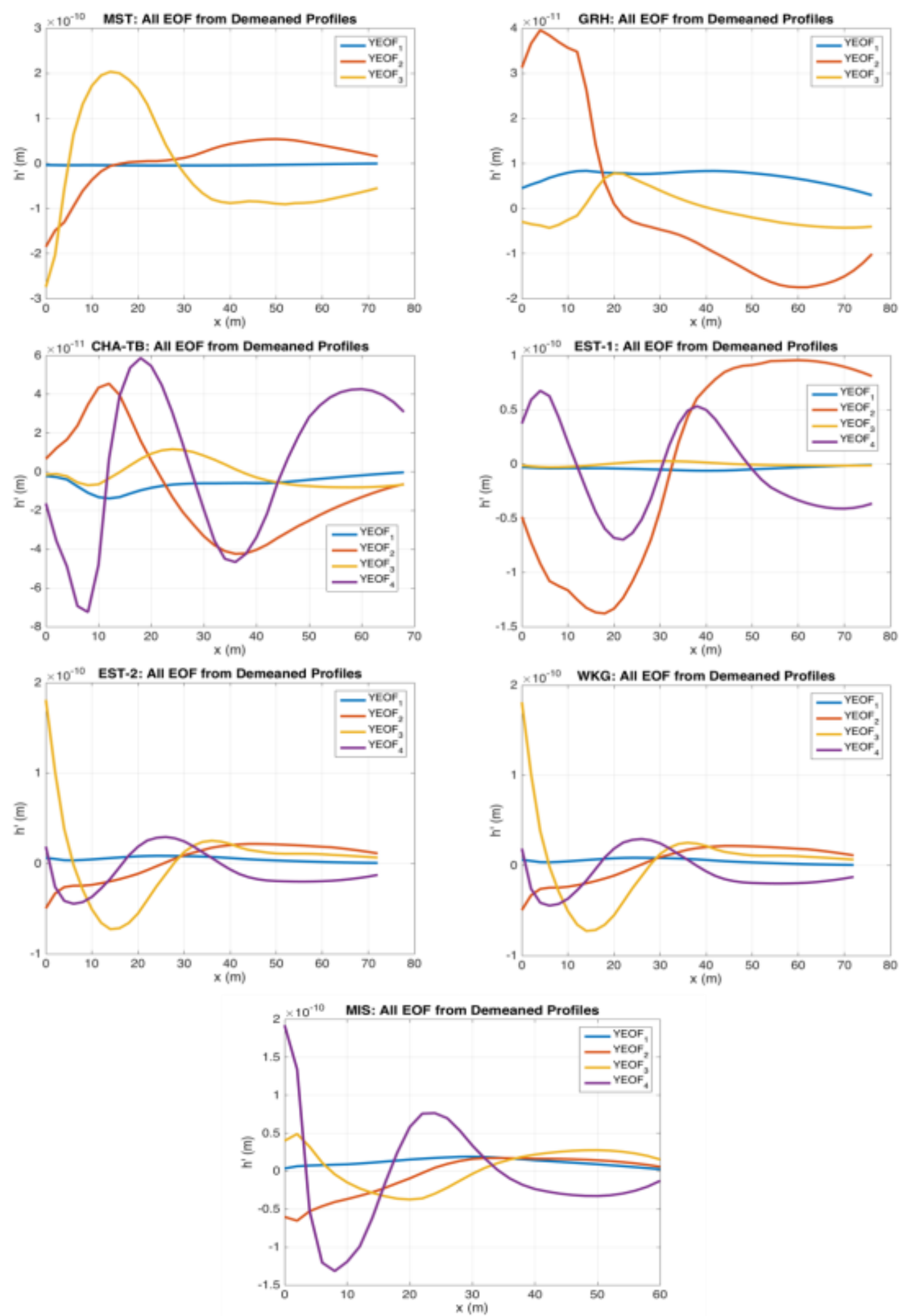

Figure 9. All eigenfunctions showing cross-shore variations for each beach. 


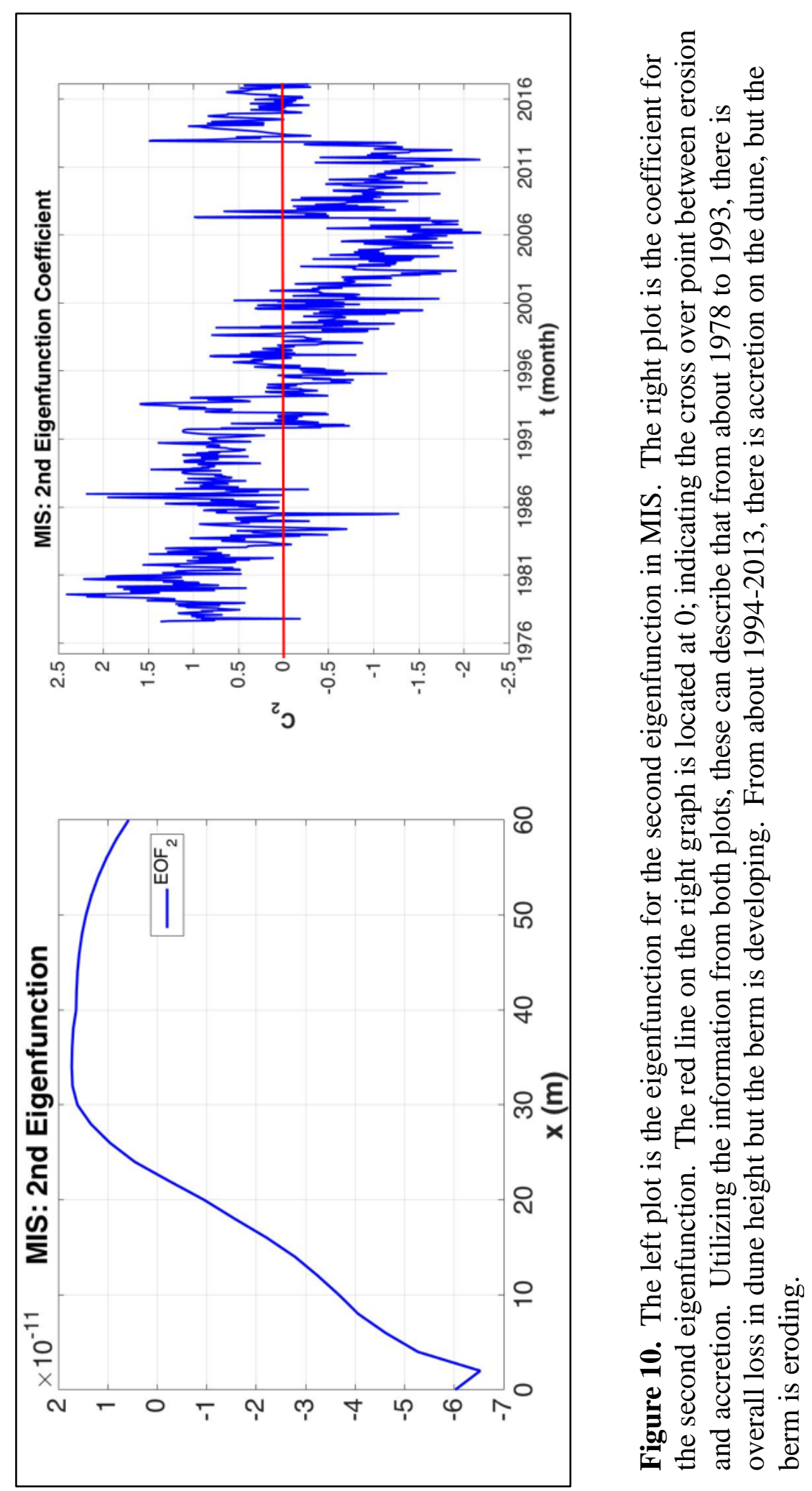




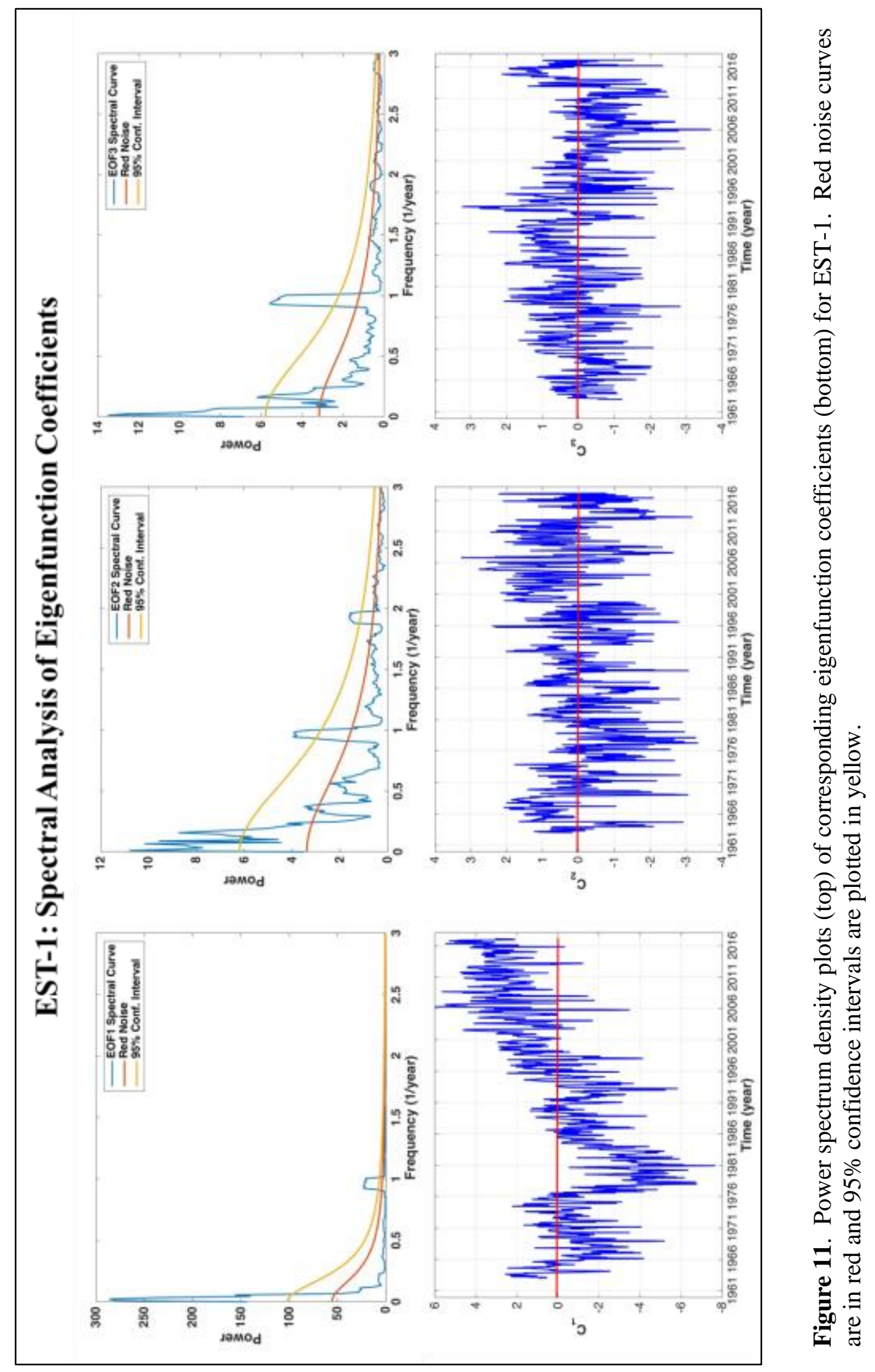




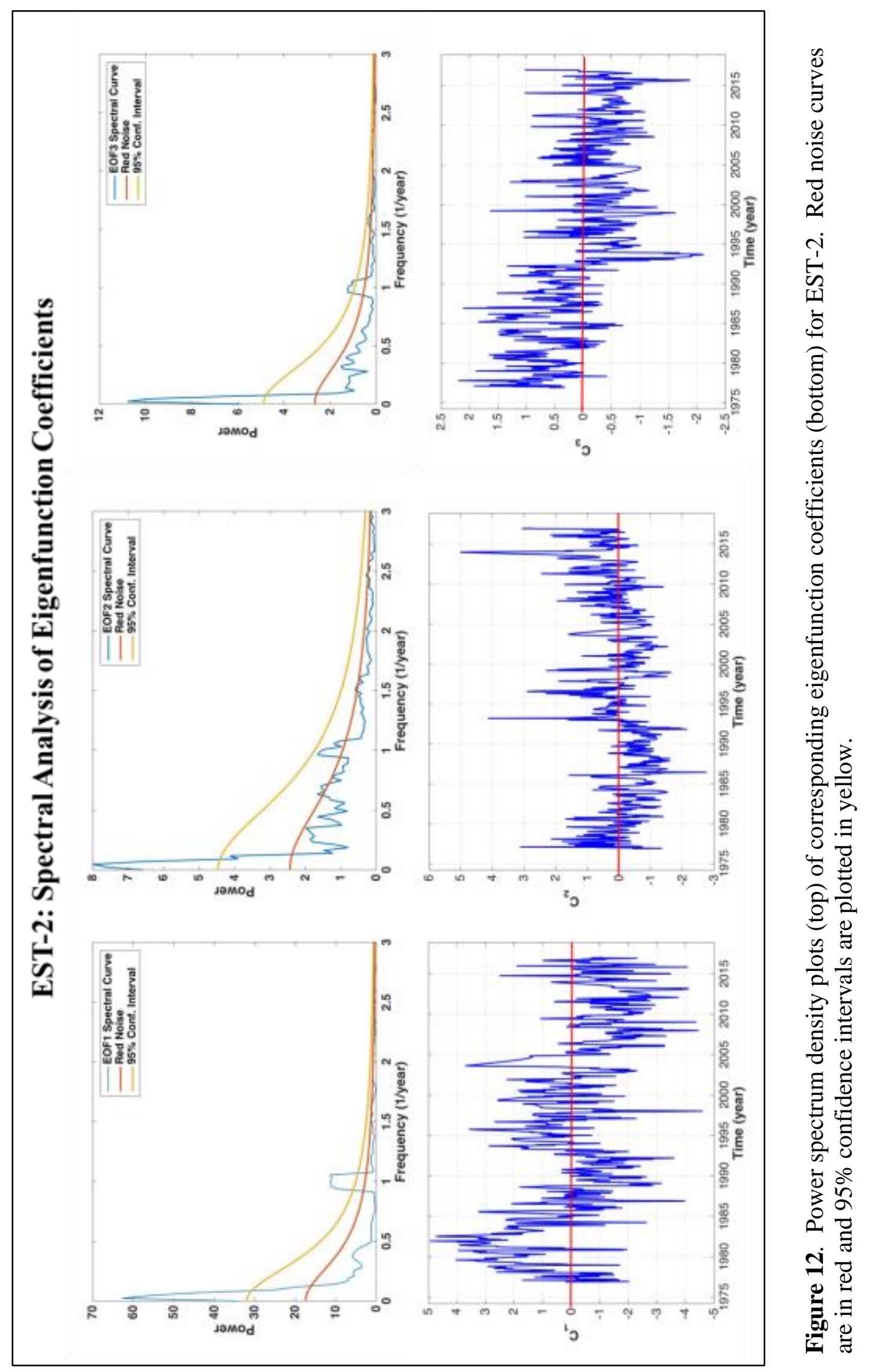




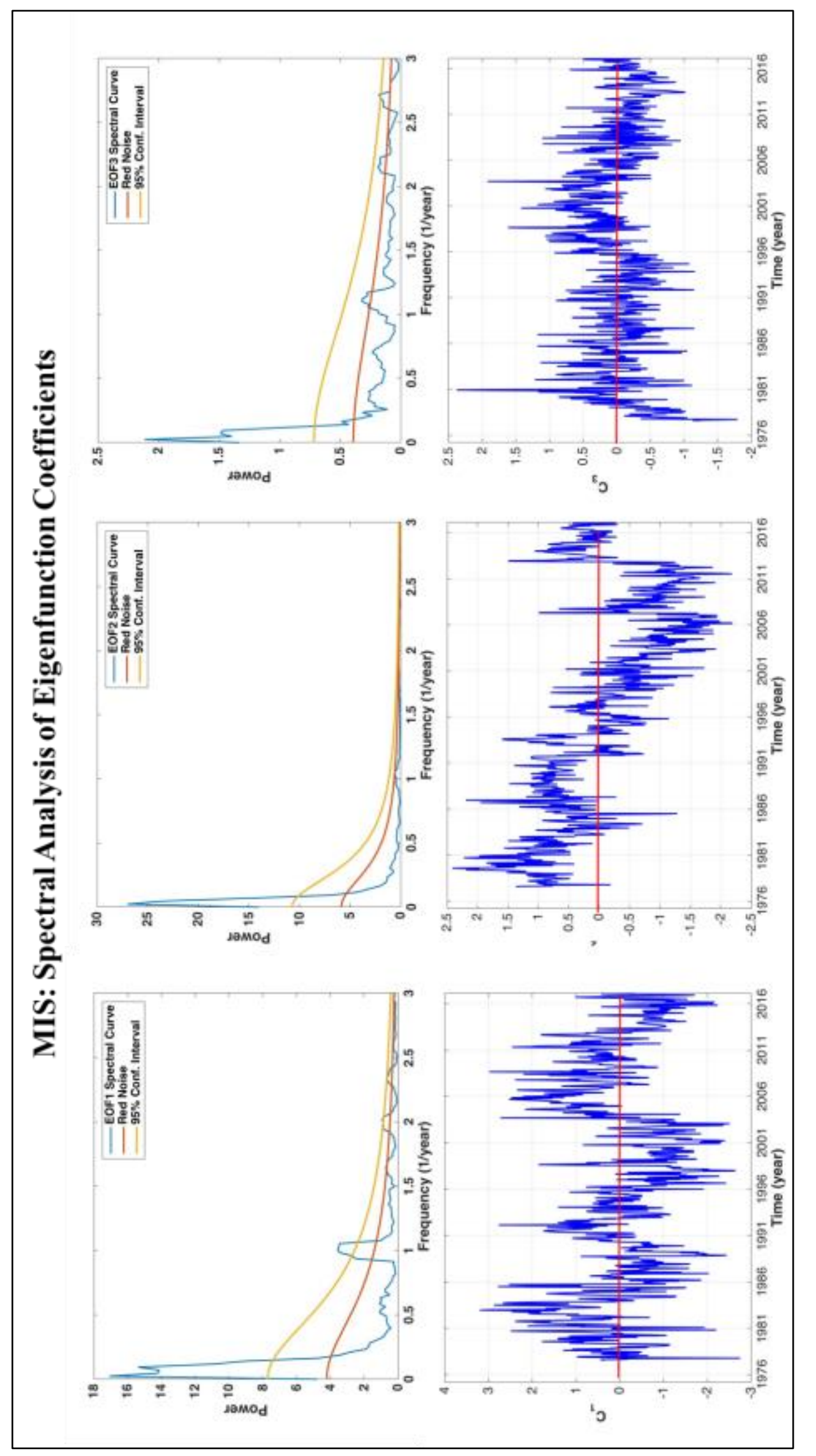

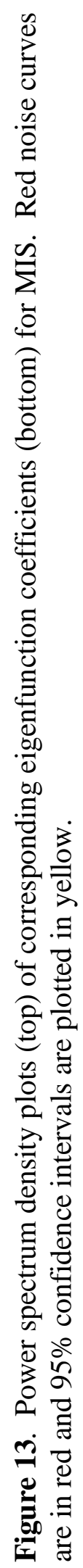



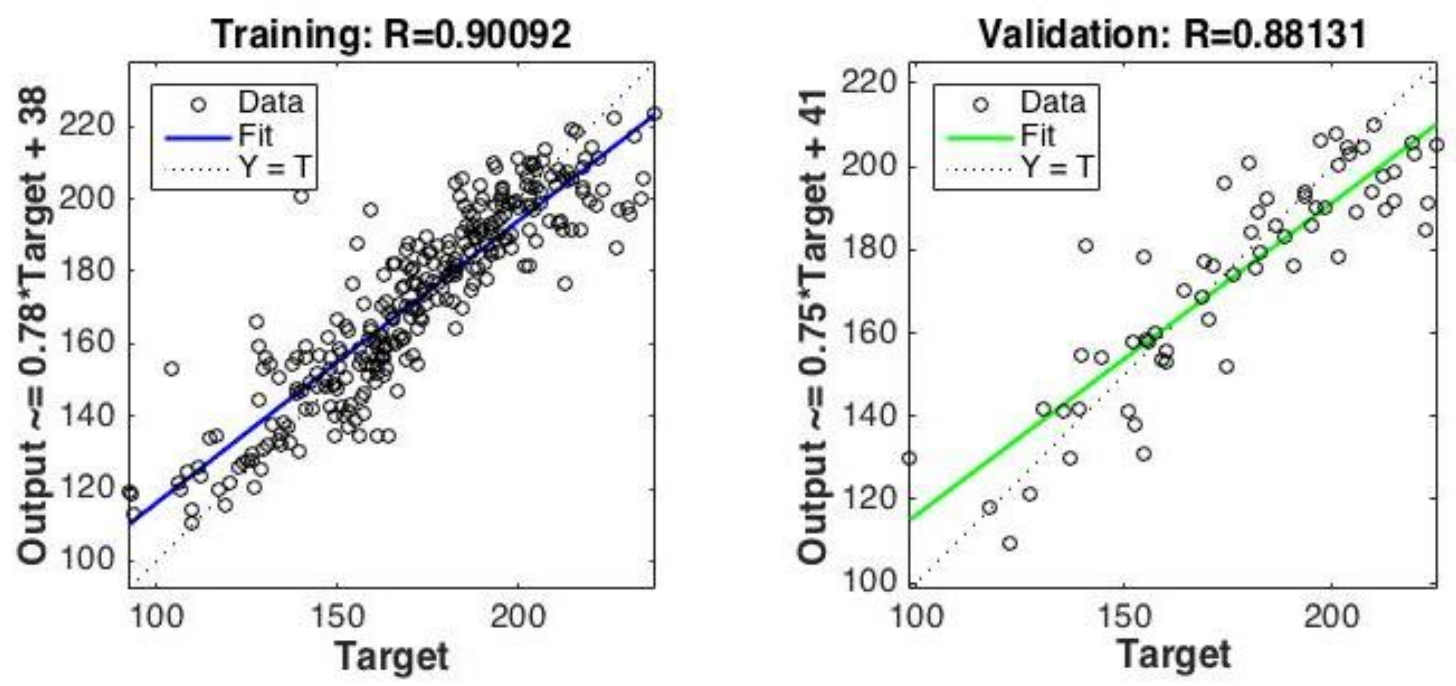

Test: $\mathbf{R}=\mathbf{0 . 8 2 2 8 8}$
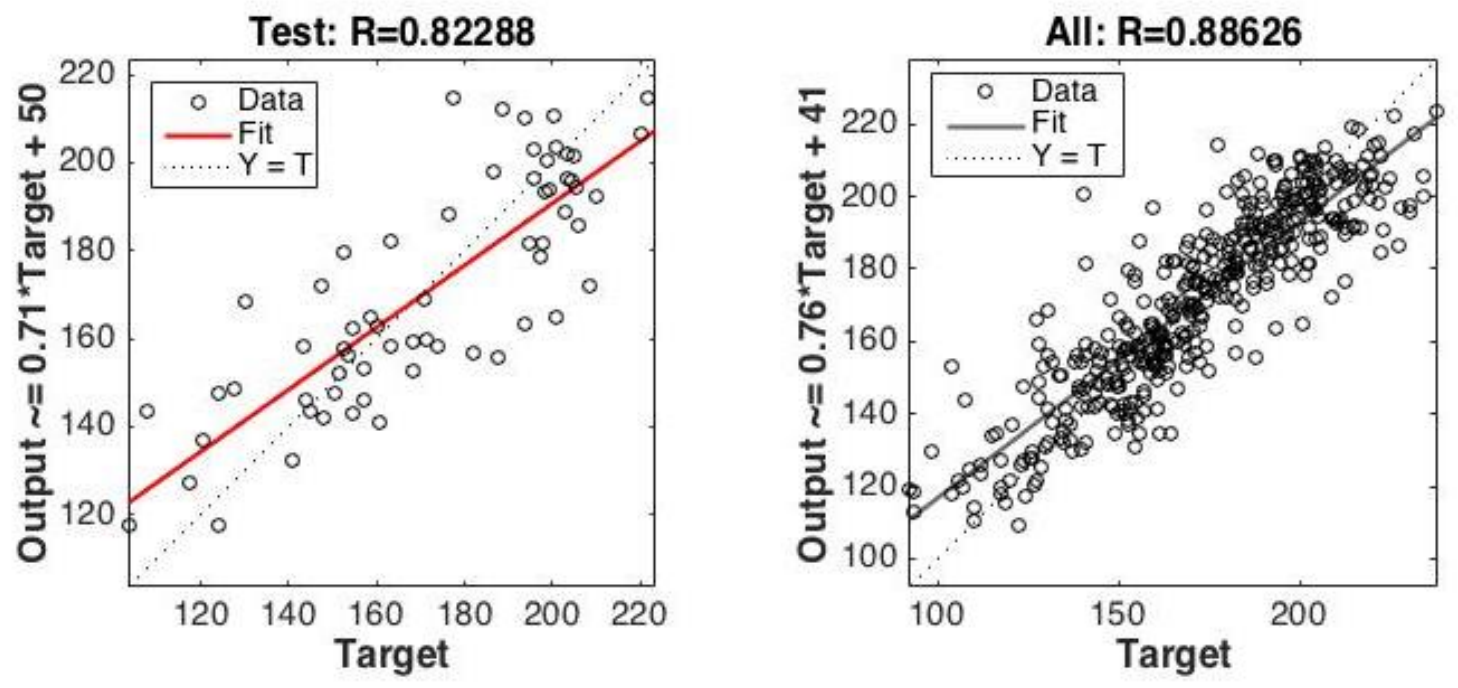

Figure 14. Resulting linear correlations between NN outputs and targets for training (upper left) of 294 time steps, validation (upper right) of 63 time steps, and testing (lower left) of 63 time steps. When the $\mathrm{NN}$ is saved and rerun on the entire timeseries dataset (420 time steps) the resulting linear correlation is $\mathrm{R}=0.8826$ (lower right). 

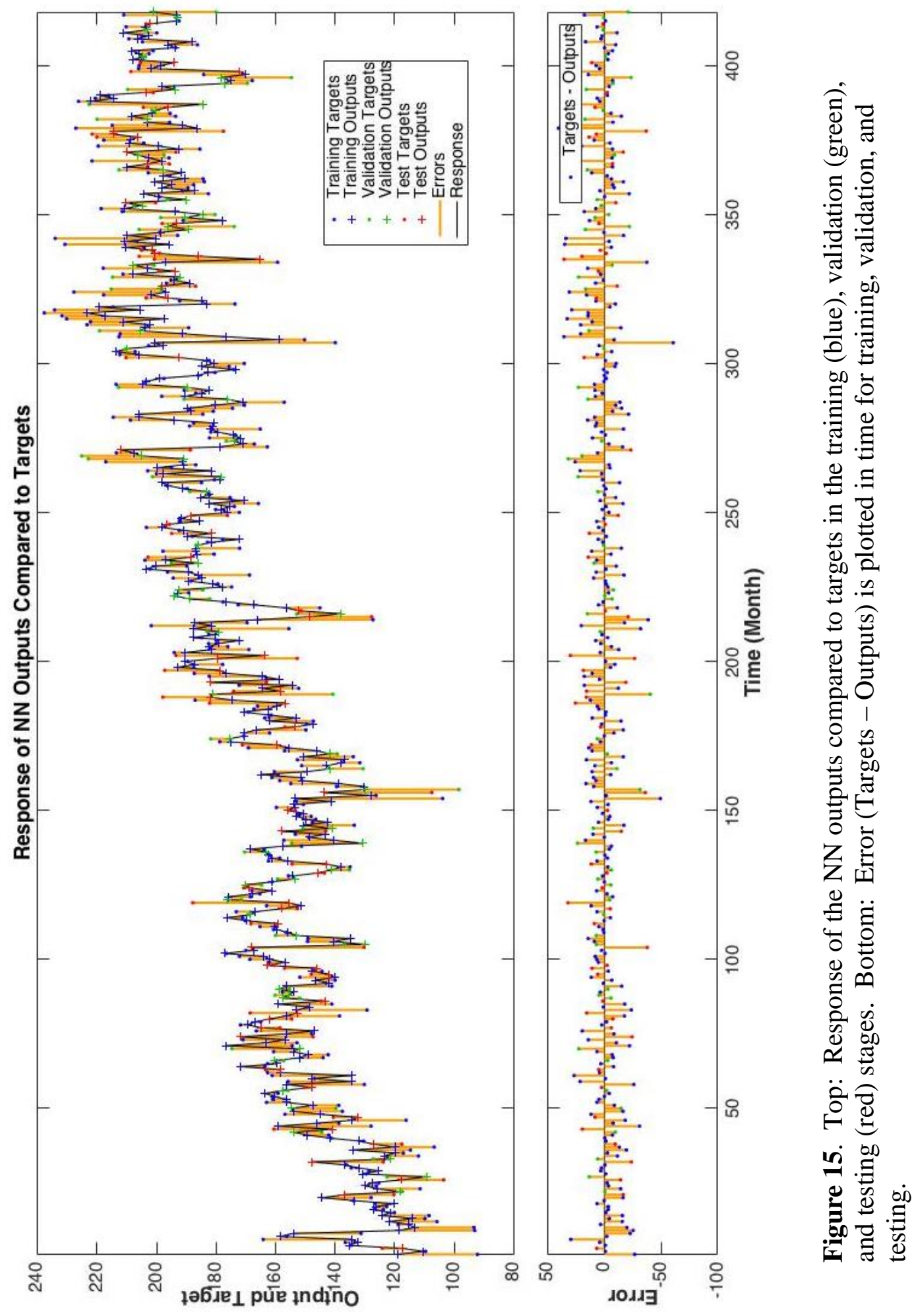


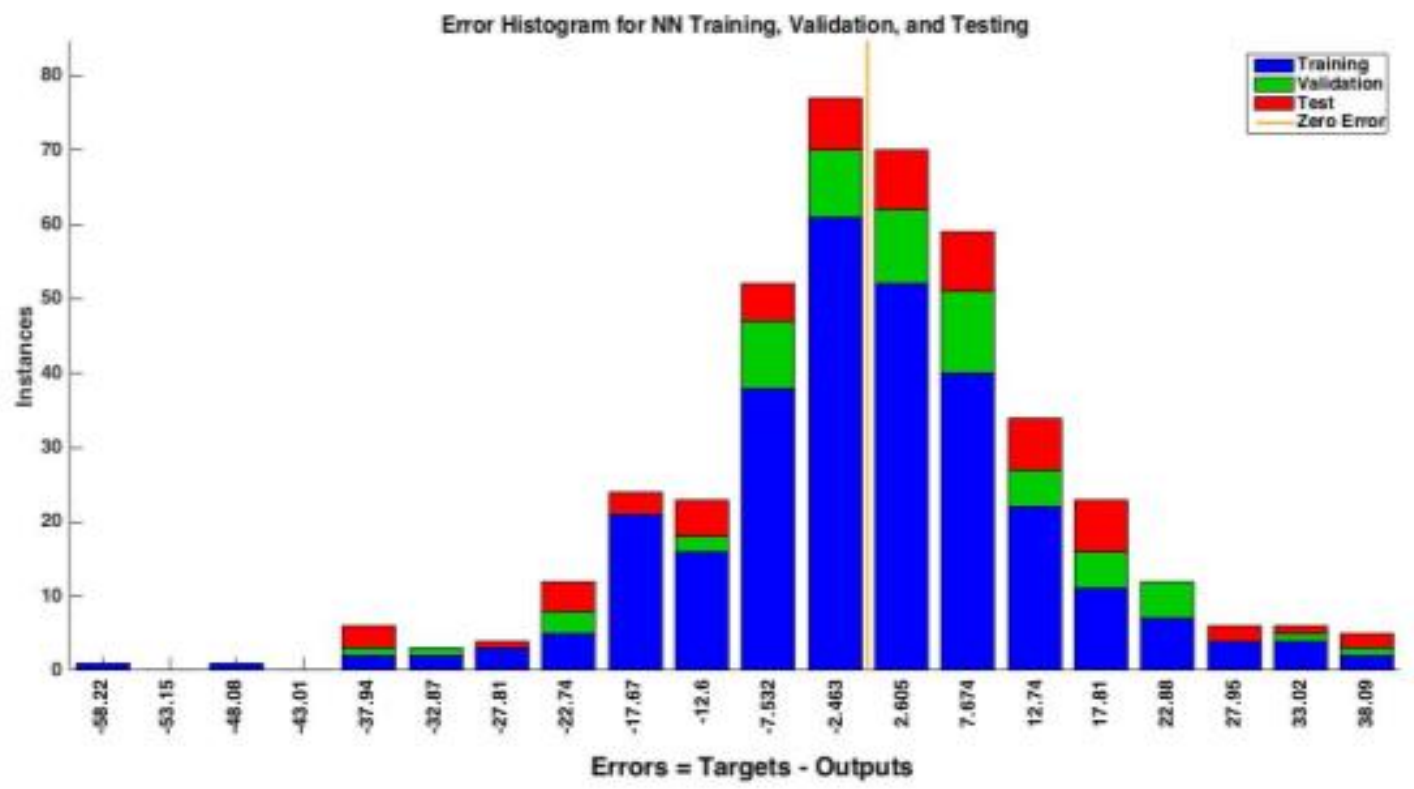

Figure 16. Error histogram of $\mathrm{NN}$ training (blue), validation (green), and testing (red). 


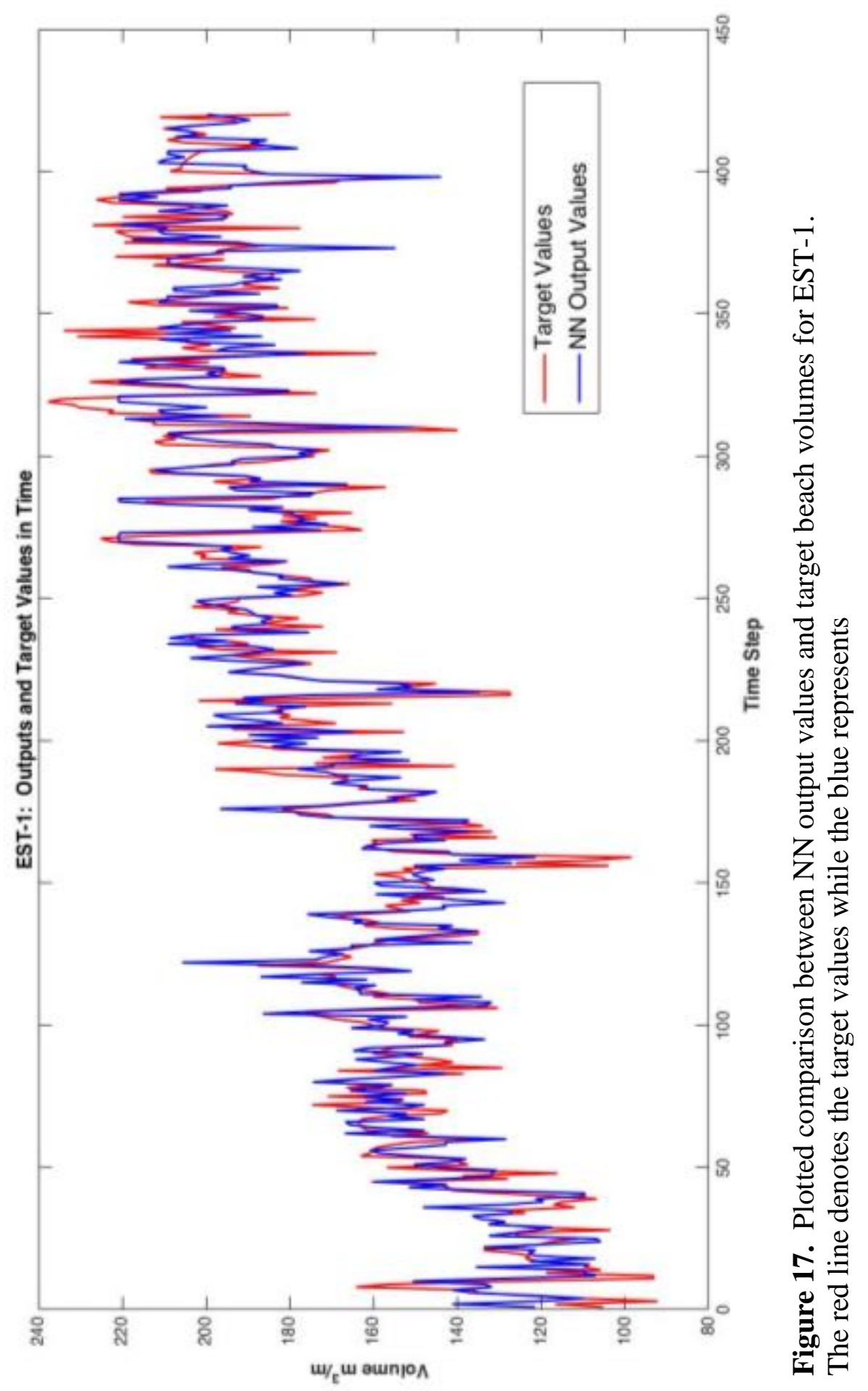




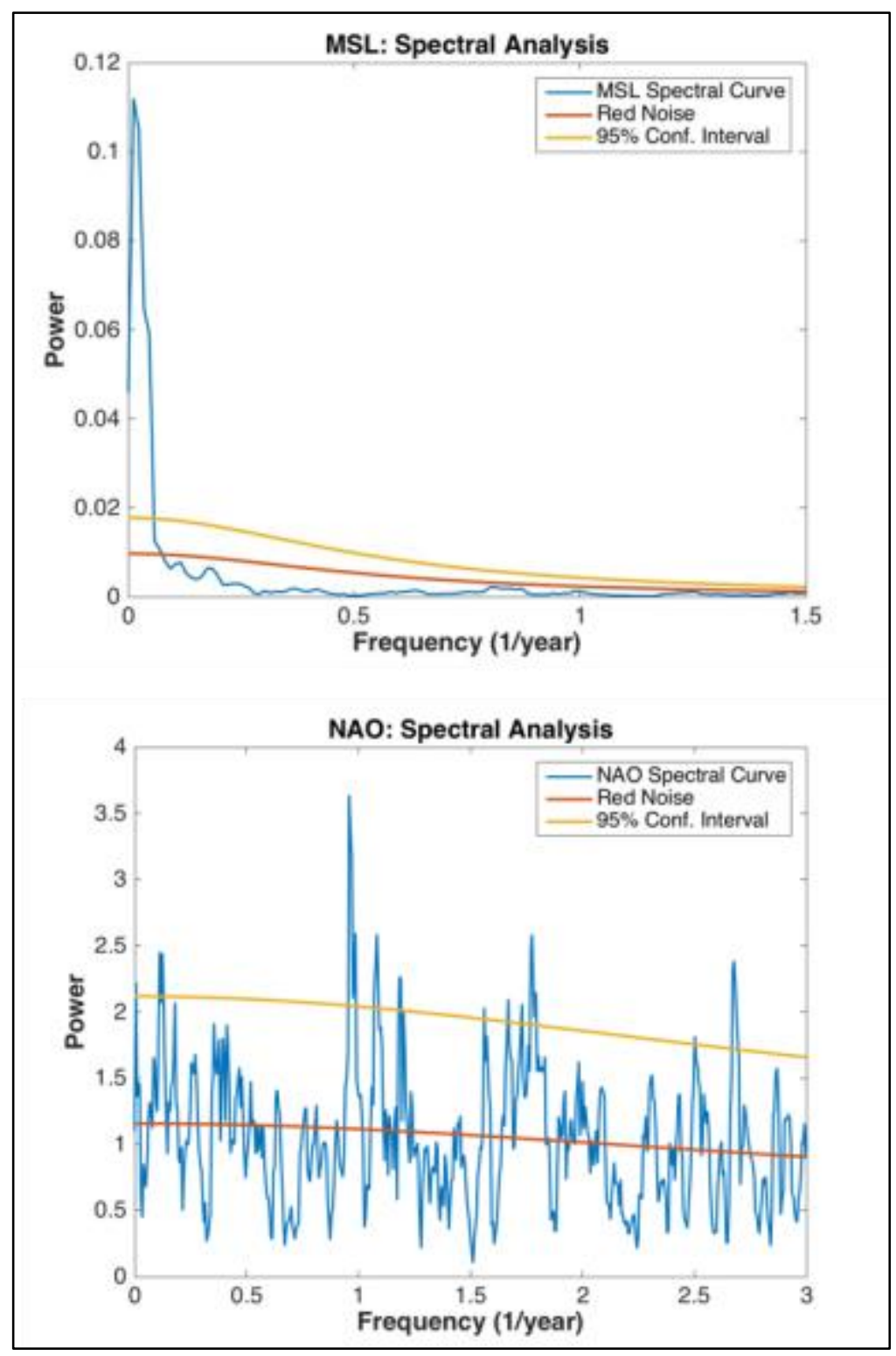

Figure 18. Above: Spectral curve for 61 years of mean sea level data from Newport, RI tide gauge. Below: Spectral curve for 128 years of NAO monthly index data. Red noise curves are in red while $95 \%$ confidence intervals are plotted in yellow. 


\section{Appendix A}

\section{Instructions for Processing LiDAR Data}

(Created by Sierra Davis 9/22/16)

- Processing the POS Data

- The first step in processing LiDAR data is processing the POS data so that the LiDAR scans can be properly georeferenced.

1. Open POSPac MMS 7.1 (currently located on desktop)

2. File $\rightarrow$ New Project

3. Save project and give it an appropriate name

4. Import POS data

5. Select POS data files $\rightarrow$ Click Import

6. Files will be exported to "Mission 1" folder that was created when the project was created.

7. Find "vnav_Mission1.out" $\rightarrow$ This is the trajectory file for the POSpac project.

- Processing the LiDAR (Ilris Data)

- This next step can occur after POS data has been processed as you use the sbet_Mission1.out $\boldsymbol{O} \boldsymbol{R}$ vnav_Mission1.out file to georeference the Ilris data.

1. Open Parser (currently located on desktop within "Parser Files" folder)

2. File $\rightarrow$ Load scan project

3. Load LiDAR scan data desired

4. Within Settings:

a. Output File

i. Output file format: XYZ File

ii. Check boxes " $\mathrm{X}, \mathrm{Y}, \mathrm{Z}$ and 8-bit Scaled Intensity OR 24-bit Texture" (USE 24-bit Texture if software you are using uses RGB)

b. Color Channel

i. Keep all default settings

c. Shot Alignment and Reduction

i. Keep all default settings

d. Pantilt Transform

i. Keep all default settings

e. Unit Attitude Correction

i. Keep all default settings

f. Apply Georef Transform

i. Check "apply geo-reference transform"

ii. Inertial reference system file type: Applanix SBET

iii. Import file with structure similar to: sbet_Mission1.out OR vnav_Mission1.out

iv. Check "Use lever arm and boresight angles in the parameter file"

v. Import file with structure similar to: boresite.txt (created previously)

g. Atmospheric Correction 
i. Keep all default settings

h. Miscellaneous

i. "Move origin to Cartesian coordinate system to bolt hole" should be checked

i. Click "Save Preferences" (for EACH line, otherwise settings do NOT save)

j. Click "OK"

k. Click "Parse" (Do NOT be in destination folder in any finder window, it could delete the destination folder!)

5. Files should now be in XYZ format in destination folder 


\section{Bibliography}

Bergaya, F., Theng, B. K. G., \& Lagaly, G. (2011). Handbook of Clay Science. Elsevier.

Boothroyd, J. C., Friedrich, N. E., \& McGinn, S. R. (1985). Geology of Microtidal Coastal Lagoons: Rhode Island. Marine Geology, 63, 35-76.

Chunlüe, Z. (2016). Empirical Orthogonal Function (EOF) analysis (No. 1.0). MATLAB Central File Exchange. Retrieved from https://www.mathworks.com/matlabcentral/fileexchange/54416-empiricalorthogonal-function--eof--analysis

Dahlquist, G., \& Björck, A. (2008). Numerical Methods in Scientific Computing: Volume 1 (Vol. 1). Philadelphia: Society for Industrial and Applied Mathematics.

Davis, R. A., \& Hayes, M. O. (1984). What is a Wave-Dominated Coast? Marine Geology, 60, 313-329.

Dean, R. G., \& Dalrymple, R. A. (2004). Coastal Processes with Engineering Applications. Cambridge: Cambridge University Press.

Durkee, J. D., Frye, J. D., Fuhrmann, C. M., Lacke, M. C., Jeong, H. G., \& Mote, T. L. (2008). Effects of the North Atlantic Oscillation on precipitation-type frequency and distribution in the eastern United States. Theoretical and Applied Climatology, 94(1-2), 51-65. https://doi.org/10.1007/s00704-0070345-x 
Frihy, O. E., \& Lotfy, M. F. (1997). Shoreline changes and beach-sand sorting along the northern Sinai coast of Egypt. Geo-Marine Letters, 17(2), 140-146. https://doi.org/10.1007/s003670050019

Gevrey, M., Dimopoulos, I., \& Lek, S. (2003). Review and comparison of methods to study the contribution of variables in artificial neural network models. Ecological Modelling, 160(3), 249-264. https://doi.org/10.1016/S0304$3800(02) 00257-0$

Goy, J. L., Zazo, C., \& Dabrio, C. J. (2003). A beach-ridge progradation complex reflecting periodical sea-level and climate variability during the Holocene (Gulf of Almería, Western Mediterranean). Geomorphology, 50(1), 251-268. https://doi.org/10.1016/S0169-555X(02)00217-9

Grilli, S. (2000). Matlab Functions. Matlab, Ocean Engineering Department, University of Rhode Island.

Hashemi, M. R., Ghadampour, Z., \& Neill, S. P. (2010). Using an artificial neural network to model seasonal changes in beach profiles. Ocean Engineering, 37(14-15), 1345-1356. https://doi.org/10.1016/j.oceaneng.2010.07.004

Horrillo-Caraballo, J. M., \& Reeve, D. E. (2008). An investigation of the link between beach morphology and wave climate at Duck, NC, USA: The link between beach morphology and wave climate. Journal of Flood Risk Management, 1(2), 110-122. https://doi.org/10.1111/j.1753-318X.2008.00013.X

Hubeny, J. B. (2002). Elevation Profiling of Eight Barrier Beaches on Rhode Island's South Shore: September 2000 to August 2001. ResearchGate. Retrieved from https://www.researchgate.net/publication/264845938_Elevation_Profiling_of_ 
Eight_Barrier_Beaches_on_Rhode_Island's_South_Shore_September_2000_t o_August_2001

Hubeny, J. B., King, J. W., \& Reddin, M. (2011). Northeast US precipitation variability and North American climate teleconnections interpreted from late Holocene varved sediments. Proceedings of the National Academy of Sciences, 108(44), 17895-17900.

Hubeny, J. B., King, J. W., \& Santos, A. (2006). Subdecadal to multidecadal cycles of Late Holocene North Atlantic climate variability preserved by estuarine fossil pigments. Geology, 34(7), 569-572.

Hurrell, J., \& NCAR. (2017). The Climate Data Guide: Hurrell North Atlantic Oscillation (NAO) Index (station-based). Retrieved from https://climatedataguide.ucar.edu/climate-data/hurrell-north-atlanticoscillation-nao-index-station-based

Hurrell, J. W. (1995). Decadal Trends in the North Atlantic Oscillation: Regional Temperatures and Precipitation. Science, 269(5224), 676-679. https://doi.org/10.1126/science.269.5224.676

Jon C. Boothroyd, Scot M. Graves, \& Christopher W. Galagan. (1988). The Rhode Island Long-Term Beach Profile Network: 1986-1988 Data (Technical Report No. 8-SRG). Retrieved from http://nsgl.gso.uri.edu/riu/riut88004.pdf Karunarathna, H., Horrillo-Caraballo, J., Kuriyama, Y., Mase, H., Ranasinghe, R., \& Reeve, D. E. (2016). Linkages between sediment composition, wave climate and beach profile variability at multiple timescales. Marine Geology, 381, 194-208. https://doi.org/10.1016/j.margeo.2016.09.012 
Karunarathna, H., \& Reeve, D. E. (2013). A hybrid approach to model shoreline change at multiple timescales. Continental Shelf Research, 66, 29-35. https://doi.org/10.1016/j.csr.2013.06.019

Lacey, E. M., \& Peck, J. A. (1998). Long-term beach profile variations along the south shore of Rhode Island, USA. Journal of Coastal Research, 1255-1264.

Landscheidt, T. (2000). Solar Forcing of El Niño and La Niña (Vol. 463, p. 135). Presented at the The Solar Cycle and Terrestrial Climate, Solar and Space weather. Retrieved from http://adsabs.harvard.edu/abs/2000ESASP.463..135L

Larson, M., Capobianco, M., \& Hanson, H. (2000). Relationship between beach profiles and waves at Duck, North Carolina, determined by canonical correlation analysis. Marine Geology, 163(1-4), 275-288. https://doi.org/10.1016/S0025-3227(99)00119-X

Larson, M., \& Kraus, N. C. (1994). Temporal and spatial scales of beach profile change, Duck, North Carolina. Marine Geology, 117, 75-94.

Lorenz, E. N. (1956). Empirical Orthogonal Functions and Statistical Weather Prediction. Massachusetts Institute of Technology, Department of Meteorology.

Masselink, G., Hughes, M., \& Knight, J. (2011). Introduction to Coastal Processes and Geomorphology, Second Edition (2 edition). London: Routledge.

Morton, R. W., Bohlen, W. F., Aubrey, D. G., \& Miller, M. C. (1984). Beach Changes at Misquamicut Beach Rhode Island, 1962-1973. DTIC Document. Retrieved from 
http://oai.dtic.mil/oai/oai?verb=getRecord\&metadataPrefix=html\&identifier= ADA150233

Neill, S. P., Elliott, A. J., \& Hashemi, M. R. (2008). A model of inter-annual variability in beach levels. Continental Shelf Research, 28(14), 1769-1781. https://doi.org/10.1016/j.csr.2008.04.004

Nestorov, I., Rowland, M., Hadjitodorov, S. T., \& Petrov, I. (1999). Empirical versus mechanistic modelling: comparison of an artificial neural network to a mechanistically based model for quantitative structure pharmacokinetic relationships of a homologous series of barbiturates. AAPS PharmSci, 1(4), 513.

Nicholls, R. J., \& Cazenave, A. (2010). Sea-Level Rise and Its Impact on Coastal Zones. Science, 328(5985), 1517-1520. https://doi.org/10.1126/science.1185782

Ruggiero, P., Voigt, B., \& Kaminsky, G. (2000). Beach monitoring for enhanced decision-making. In Coastal Society 17th Conference Coasts at the Millennium (pp. 9-12). Retrieved from http://nsgl.gso.uri.edu/oresu/oresuc00002/pdffiles/papers/087.pdf

Sheridan, S. C. (2003). North American weather-type frequency and teleconnection indices. International Journal of Climatology, 23(1), 27-45. https://doi.org/10.1002/joc.863

Sorensen, R. M. (2005). Basic Coastal Engineering (3rd edition). New York: Springer. 
Stive, M. J., Aarninkhof, S. G., Hamm, L., Hanson, H., Larson, M., Wijnberg, K. M., ... Capobianco, M. (2002). Variability of shore and shoreline evolution. Coastal Engineering, 47(2), 211-235.

Stive, M. J., \& De Vriend, H. J. (1995). Modelling shoreface profile evolution. Marine Geology, 126(1-4), 235-248.

Thomas, T., Phillips, M. R., \& Williams, A. T. (2010). Mesoscale evolution of a headland bay: Beach rotation processes. Geomorphology, 123(1-2), 129-141. https://doi.org/10.1016/j.geomorph.2010.06.018

Thomas, T., Phillips, M. R., Williams, A. T., \& Jenkins, R. E. (2011). Short-term beach rotation, wave climate and the North Atlantic Oscillation (NAO). Progress in Physical Geography, 35(3), 333-352. https://doi.org/10.1177/0309133310397415

United States. (2006). Coastal Engineering Manual (6th ed.). Washington, D.C.: U.S. Army Corps of Engineers.

Vaníček, P. (1991). Vertical Datum and NAVD 88. Surveying and Land Information Systems, 51(2), 83-86.

Vinhateiro, N. D. (2012). Mechanisms of shoreline change on the Rhode Island south coast: Past, present, and future. Dissertations and Master's Theses (Campus Access), 1-163.

Wachinger, C., Golland, P., \& Reuter, M. (2014). BrainPrint : Identifying Subjects by Their Brain. In Medical Image Computing and Computer-Assisted Intervention-MICCAI 2014 (pp. 41-48). Springer, Cham. https://doi.org/10.1007/978-3-319-10443-0_6 
Winant, C. D., Inman, D. L., \& Nordstrom, C. E. (1975). Description of Seasonal Beach Changes Using Empirical Eigenfunctions. Journal of Geophysical Research, 80(15). Retrieved from http://pordlabs.ucsd.edu/ltalley/sio219/Winantetal1975.pdf 